\title{
Modelling Best Oil Palm Site Planting in Njimom, West-Cameroon: A GIS-Analysis Combining Weighted Linear Combination, Fuzzy Analytical Hierarchy Process and Utility Function
}

\author{
Alfred Homère Ngandam Mfondoum ${ }^{1,2 *}$, Roland Bruno Ngouyamsa Mfondoum ${ }^{3}$, \\ Pauline Ngùet Wokwenmendam ${ }^{4}$, Paul Gérard Gbetkom ${ }^{5}$, Marthe Ntengo ${ }^{6}$
}

${ }^{1}$ Stats N' Maps, Private Consulting Firm, Dallas, Texas, USA

${ }^{2}$ Department of Geography, Laboratory of Natural Resources Management, University of Yaoundé, Yaoundé, Cameroon

${ }^{3}$ Department of Computer and Data Sciences, University of Prague, Prague, Czech Republic

${ }^{4}$ Mining and Geological Research Institute, Volcanological and Geophysical Unit, Yaoundé, Cameroon

${ }^{5}$ Department of Geography, University of Aix-Marseille, Marseille, France

${ }^{6}$ Department of Sciences, Laboratory of Geology, Richland College, Dallas, Texas, USA

Email: *ngandamh@yahoo.com, mfondoum2000@gmail.com, nguetpauline@yahoo.fr, paul-gerard.gbetkom@etu.univ-amu.fr,

ntengo.marthe@yahoo.com

How to cite this paper: Mfondoum, A.H.N., Mfondoum, R.B.N., Wokwenmendam, P.N., Gbetkom, P.G. and Ntengo, M. (2019) Modelling Best Oil Palm Site Planting in Njimom, West-Cameroon: A GIS-Analysis Combining Weighted Linear Combination, Fuzzy Analytical Hierarchy Process and Utility Function. Journal of Geographic Information System, 11, 138-165.

https://doi.org/10.4236/jgis.2019.112011

Received: March 14, 2019

Accepted: April 13, 2019

Published: April 16, 2019

Copyright $\odot 2019$ by author(s) and Scientific Research Publishing Inc. This work is licensed under the Creative Commons Attribution International License (CC BY 4.0). http://creativecommons.org/licenses/by/4.0/

\begin{abstract}
Oil Palm (Elaeis guineensis Jacq.) has recorded a boom production the last decades and its main productive zone is inside the tropics that meet the best biophysical conditions. Investors as well as geospatial practitioners are increasingly interested on the best growing and harvesting conditions. So said, the aim of this paper is to select the best oil palm planting site through the best methods combination. The study area is the district of Nimom located in the west-Cameroon, transitional between the equatorial and the climatic zones. In the same GIS environment, the Weighted Linear Combination (WLC) and Fuzzy Analytic Hierarchy Process (FAHP) respectively highlight the subtle differences between capability and suitability, while the Utility Function (UF) helps to assess the consideration of sustainability aspects. The first results consist in eight layers representing natural conditions, that is rainfall, temperatures, sunshine, slope, elevation, soil richness, soil moisture and forest cover, recoded in six classes ranked from 5 to 0 according to the FAO standardised scale. They are crossed using the straightforward method of WLC to give the "Capability layer". The second results consist in three layers related to the social-economical constraints for production, as built-up
\end{abstract}


area, distance to road and distance to rivers. These layers are recoded in binary with 1 and 0 , they are weighted by the FAHP priority vector and membership approach to give the "suitability layer". Then, the number of occurrences of each aspect of the sustainability is counted in each of the two preceding processes to perform the UF. The resulting value, that is 0.542 for the capability process and 0.315 for the suitability process, serves to weight their respective layers, and their sum gives the final map with the best oil palm site planting in the northern part of the study area, on about 34,950 ha, representing $44.8 \%$ of Njimom district.

\section{Keywords}

Oil Palm, GIS, WLC, FAHP, UF, Capability, Suitability, Sustainability

\section{Introduction}

Oil Palm (Elaeis guineensis Jacq.) is one amongst others world's most important tropical tree crops. It is mainly grown for the industrial production of vegetable oil [1]. The different uses include the manufacture of soaps, detergents and other toiletries in oleo chemical industries for the Kernel Oil Palm [2] [3], as well as ingredient in many foods, in leather, meal and chemical industries, for the Crude Oil Palm [4]. According to [5], an estimated 50 percent of packaged products sold in supermarkets contains some of the ubiquitous oil. More recently, it has been involved in the biodiesel production. Further, [6] [7] [8] [9] estimate that future increases in demand for vegetable oils will be primarily satisfied by palm oil rather than by other vegetable oils. This explains the boom of the production in the last decades, representing more than $30 \%$ of the global vegetable oil production [10], and making it the world's most widely consumed edible oil [4] [11]. Demand for palm oils is expected to double by 2020 [12].

The main productive zone is located inside the tropics between $10^{\circ} \mathrm{N}$ and $10^{\circ} \mathrm{S}$ of the Equator, where biophysical and environmental conditions are combined for its growth [1] [11]. For these reasons, the 43 first productive nations are tropical countries located in Southeast Asia, Africa, Central and South America [3] [13]. In most of these countries, governments increasingly promote its cultivation as a major contributor to poverty alleviation, as well as food and energy independence [14]. Then, palm trees are grown in two ways. They are observed in village gardens where they provide oil for local consumption with relatively lower yield and oil quantity. However, for industrial purposes, palm trees are mainly grown and harvested over large uniform areas of 3000 to 5000 ha [1] [11]. The grower or investor must then use modern methods for best harvesting and economical benefits [11]. He should integrate at the same time the two others dimensions of the sustainability, which are the social development and the environment protection or restoration. Geospatial techniques show ability to face this challenge and the processing's results are widely requested by enterprises, NGO's or others individuals who want to invest in any agricultural activity. 
Indeed, the improvement and accuracy of geospatial techniques also known as Geographic Information Systems (GIS) are notable today in real world decision-making processes, including for agriculture practices [15]. Either it is for the best site selection, economical benefits, spatial expansion or monitoring, remote sensing and spatial analysis have a significant potential to support modern oil palm cultivation. [6] has computed a global suitability model for oil palm cultivation by combining maps of each relevant biophysical factor that is climate, soil and topography. A specific protocol was designed and tested by [16] for oil palm suitability land in South-West Cameroon. [17] has predicted deforestation and assessed land suitability for oil palm in Papua New Guinea. Recently, [18] has models irrigated agriculture suitability to achieve food security in an arid environment. [19] has combined fuzzy indicators to evaluate agricultural land suitability.

Once the land suitability is assessed and the crops are growing, the focus concerns the monitoring for different purposes as land use, deforestation, age, counting, diseases, etc. Using Landsat ETM+ satellite images, [20] has mapped oil palm land use in Malaysia. The same way, [21] has projected oil palm expansion in Indonesia, Malaysia and Papua New Guinea covering the period 2010 to 2050. [4] [22]-[27] have successfully used Landsat and SPOT satellites imaging data to identify oil palm growing areas and to map differences in palm groves stages. [28] and [29] did the same using LiDAR data, PALSAR 50-m and WorldView-3 Imagery, for oil palm plantations extension, palm trees counting and age estimation. [30] has generated smallholder oil palm distribution map using optical satellite data of SPOT 7 and investigated the backscatter values of ALOS PALSAR-2 with height and age of oil palm in mineral soil and peatland. [27] and [31] have tested a multi-sensor data fusion to map African palm. [32] has used remote sensing for biomass estimation, while [33] has linked agricultural strategies of palm groves, biomass and the produced energy for a long-term management of oil palm resources. [34] has focused on the conversion of forest areas into oil palm cultivation, [35] did so too in the South-west Cameroon region, correlating oil palm expansion, deforestation and informal mills, and [36] assessed the groves. [22] and [37] have indicated the carbon stock of oil palm and its environmental effects. As overall, [38] recently reviewed all these remote sensing applications and seven groups stand out as, land cover classification, change detection, tree counting, age estimation, estimation of AGB and carbon production, pest and disease detection, and yield estimation.

In this study, the main objective is a spatial modelling to select the best oil palmsite for sustainable planting and growth conditions, in terms of suitability/capability evaluation [39] [40]. Suitability most often refers to social-economical promise, and point out the frameworks used to assess the capacity of land in supporting primary production [15] [41]. Whereas capability usually indicates physical or natural environmental potential as climate, relief, soils, hydrology and vegetation, to support a given land use [15] [42]. These subtle differences are considered in this paper to better integrate the three aspects of the sustainable agri- 
cultural development, that is, conserving land, water, plant and animal genetic resources, environmentally non-degrading, technically appropriate, economically viable and socially acceptable [11].

\section{Methodology}

\subsection{General Framework}

According to [1] [11] [43] [44], oil palm plantation needs specific natural and economical conditions. For the natural aspects, climate, soil, sun exposition and physical surroundings are mainly concerned. The oil palm grows well where it is hot all the year round, with temperatures between 25 - 28 degrees Celsius, and never under 15 degrees Celsius. The palm trees should be permanently exposed to a lot of sunshine for a strong photosynthesis, so the leaves will grow larges, the fruits will ripen well, and there will be more oil in the fruits. Optimal rainfall conditions are $2000-2500 \mathrm{~mm}$ per year with a minimum of $100 \mathrm{~mm}$ per month, with $1000 \mathrm{~mm}$ and five months dry period per year as the worst moisture liveable.The land should be flat because oil palm thrives best in lowlands below 300 - $400 \mathrm{~m}$ of altitude to avoid or minimize risk erosion. Soils should be deep and permeable to enable the good development of roots, and rich enough in mineral salts in order to produce many large clusters of fruit. The moisture supply is important to regulate the temperature usually through the presence of a surrounding dense forest.

Moreover, the economics aspects depend on the type of plantation to be created. [11] distinguishes three types of oil palm plantations. A small-scale palm oil farm may cover 7.5 hectares, for usually local farmers. The medium-scale farm ranges from 10 to 500 hectares. This type of farm normally uses modern agronomic practices such as plant spacing, cover cropping, fertilization, ring weeding, pruning. Large-scale farms cover an area exceeding 500 hectares. These are state owned enterprises, established to meet the internal consumption needs of the country and provide a surplus for export. For the medium and the large sizes, factories and mills should be close of the exploitation, as well as roads infrastructures for easy transport. So said, [45] and [46] have proposed some basics frameworks of growth conditions suitability classification (Table 1). The ranking is made on a proposed scale of 5 to 0 from the optimal to the worst conditions, with mid-scales fuzzy linguistic appreciation (Table 2).

\subsection{Casting of Methods and Background Related}

The oil palm growing different conditions are enough expressive of a multi-criteria decision-making (MCDM) problem. It is mainly involved in combining information from several criteria to form a single index of evaluation [47]. Depending on the GIS analysis context, it can be qualified of resource allocation analysis or suitability/capability analysis, as in this paper [39] [40]. Then, the choice of fundamentals and supporting methods leading the analysis is based on the three aspects brought out by the planting conditions, that is, the natural ca- 
pability, the social-economical suitability and the overall sustainability. The said methods applied include the Weighted Linear Combination (WLC), the Analytical Hierarchy Process (AHP) and its fuzzy variety, and utility function (UF).

\section{- The Weighted Linear Combination (WLC)}

The WLC or simple additive weighting is one of the widely used multi-criteria evaluation (MCE) methods as a GIS-based decision rules for land suitability analysis [48] [49]. Practically, the suitability components and conditions are transposed onto maps and standardized according to the analyst' scale choice. Weighs of relative importance are assigned to each of them. Then, both weighs and standardized maps are combined using the following Equation (1):

$$
S=\sum w_{i} x_{i}
$$

Table 1. Listing of best planting/growing conditions.

\begin{tabular}{cccc}
\hline Field & Conditions & Details & Reasons \\
\hline \multirow{2}{*}{ Climate } & Rainfall & $2000-2500 \mathrm{~mm}$ & Moisture \\
& Temperatures & $25^{\circ} \mathrm{C}-28^{\circ} \mathrm{C}$ & Relative heat \\
& Sunshine & Permanent & Photosynthesis \\
Physical and & Soils & Deep and permeable & Minerals supply and \\
support & Land/Altitude & Flat/300 - $400 \mathrm{~m}$ & roots penetration \\
& Forest & Enough dense & Avoid erosion \\
& Space & At least 7.5 ha & Moisture \\
& Mills/Factories & Close & Beneficial harvesting \\
Economical & Roads/Accessibility & Close/Easy & Direct transformation \\
& & & Distribution
\end{tabular}

Table 2. Scale of conditions suitability.

\begin{tabular}{|c|c|c|c|c|c|c|}
\hline \multirow{2}{*}{ Details } & \multicolumn{6}{|c|}{ Suitability classes (From perfectly suitable $=5$ to not suitable $=0$ ) } \\
\hline & 5 & 4 & 3 & 2 & 1 & 0 \\
\hline $\begin{array}{l}\text { Annual rainfall } \\
\qquad\left(\mathrm{mm} / \mathrm{m}^{2}\right)\end{array}$ & $2000-2500$ & $2500-2875$ & $2875-3250$ & $3250-3625$ & $3625-4000$ & $>4000$ \\
\hline $\begin{array}{l}\text { Number of dry } \\
\text { months } \\
\left(<100 \mathrm{~mm} / \mathrm{m}^{2}\right)\end{array}$ & 1 & 2 & 3 & 4 & $4-5$ & $>5$ \\
\hline $\begin{array}{c}\text { Average annual } \\
\text { temperatures } \\
\left({ }^{\circ} \text { Celsius }\right)\end{array}$ & $24-33$ & $33-34$ & $34-35$ & $35-36$ & $36-38$ & $>38$ \\
\hline Soils & $\begin{array}{c}\text { Clay loam; } \\
\text { sandy clay } \\
\text { loam; silt clay } \\
\text { loam }\end{array}$ & $\begin{array}{l}\text { Sandy loam; } \\
\text { Silt loam; } \\
\text { Silt }\end{array}$ & Loam & $\begin{array}{l}\text { Clay; loamy } \\
\text { sand }\end{array}$ & Sand & \\
\hline Slope (Degree) & $<4$ & $4-9$ & $9-13$ & $13-18$ & $18-25$ & $>25$ \\
\hline Elevation (a.s.l.) & $<500$ & $500-850$ & $850-1050$ & $1050-1280$ & $1280-1500$ & $>1500$ \\
\hline
\end{tabular}


where $S$ is the suitability, $w_{i}$ is a weighting of factor $i$, and $x_{i}$ is the criterion score of factor $i$.

The AHP process sometimes supports GIS implementations of WLC, if the default weigh, 1 , should be changed.

\section{- The Fuzzy Analytical Hierarchy Process (FAHP)}

The AHP was developed in the 70's by [50] as a helping tool for decision makers to find out the "best" alternative out of several ones by considering a number of conflicting criteria [49] [50]. The process is based on the three principles, that is, decomposition, comparative judgment and the synthesis of data [50] [51] [52] [53]. Depending on the study, the fuzzy set could be incorporated with the AHP [54]. The idea of the fuzzy set theory is to deal with vagueness and no specificity inherent in human formulation of preferences, constraints, and goals [55]. The information is expressed by linguistic or fuzzy values rather than by numbers and this approach handles multiple criteria and combinations of qualitative and quantitative data [56]. The most popular fuzzy number is the Triangular Fuzzy Number (TFN), which is represented by three parameters as $l$, $m, u$, corresponding to the smallest possible value, the most promising value, and the largest possible value. For a fuzzy number denoted $\tilde{A}=(l, m, u)$, the membership function is defined as follow (Equation (2), Figure 1):

$$
\mu \tilde{A}(x)= \begin{cases}\frac{x-l}{m-l} & \text { if } l \leq x \leq m \\ \frac{u-x}{u-m} & \text { if } m \leq x \leq u \\ 0 & \text { otherwise }\end{cases}
$$

Furthermore, linguistic variables that allow the translation of natural language into logical or numerical statements are hierarchically organized as a Linguistic Fuzzy Decision Network, based on the expert's preferences or the causal relationship between the values [57] (Table 3, Figure 2, Table 4, Figure 3).

\section{- The Utility Function (UF)}

How useful is each objective to the sustainability of the oil palm cultivation? The answer to this question explains the integration of the utility function. UF is a logical attribution of values to the different baskets of consumption, such a way that the most desirable baskets receive higher values than those who are less [58]. The principle is a ranking of the consumer preferences. It is stated that a basket $\left(x_{1}, x_{2}\right)$ is preferred to a basket $\left(y_{1}, y_{2}\right)$, only if utility level $U$ of $\left(x_{1}, x_{2}\right)$ is higher than the one of $\left(y_{1}, y_{2}\right)$. Equation (3) poses the formula.

$$
\left(x_{1}, x_{2}\right)>\left(y_{1}, y_{2}\right) \text { if } U\left(x_{1}, x_{2}\right)>U\left(y_{1}, y_{2}\right)
$$

The UF used in this study is written as follow (Equation (4)):

$$
U\left(x_{1}, x_{2}\right)=x_{1}^{c /(c+d)} x_{2}^{d /(c+d)}
$$

where $c$ and $d$ are positive numbers with the relationship:

$$
c>0, d>0, c+d=1
$$




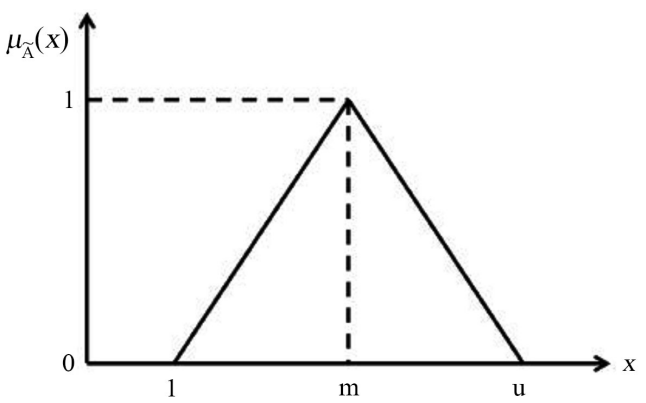

Figure 1. Illustration of a Triangular Fuzzy Number.

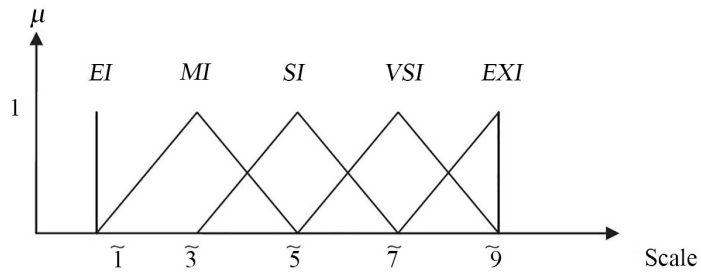

Figure 2. Membership functions of linguistic values of the fuzzy preference scale.

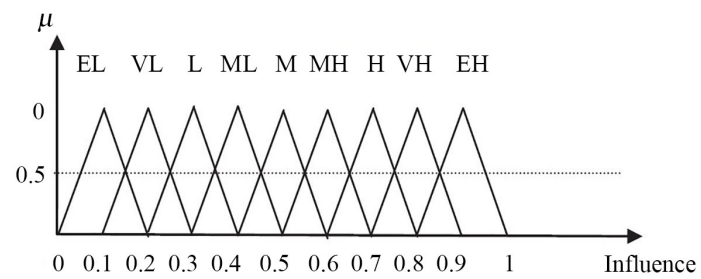

Figure 3. Membership functions of linguistic values forcausal relationships.

Table 3. Fuzzy preference scale.

\begin{tabular}{|c|c|c|c|}
\hline $\begin{array}{l}\text { Intensity of } \\
\text { fuzzy scale }\end{array}$ & Definition of linguistic values & $\begin{array}{l}\text { Triangular } \\
\text { fuzzy scale }\end{array}$ & $\begin{array}{l}\text { Triangular fuzzy } \\
\text { reciprocal scale }\end{array}$ \\
\hline$\tilde{1}$ & Equal importance (EI) & $(1,1,1)$ & $(1,1,1)$ \\
\hline$\tilde{2}$ & $\begin{array}{l}\text { Equally moderate } \\
\text { importance }\end{array}$ & $(1,2,3)$ & $(1 / 3,1 / 2,1)$ \\
\hline$\tilde{3}$ & Moderate importance & $(1,3,5)$ & $(1 / 5,1 / 3,1)$ \\
\hline$\tilde{4}$ & $\begin{array}{l}\text { Moderately strong } \\
\text { importance }\end{array}$ & $(2,4,6)$ & $(1 / 6,1 / 4,1 / 2)$ \\
\hline$\tilde{5}^{n}$ & Strong importance (SI) & $(3,5,7)$ & $(1 / 7,1 / 5,1 / 3)$ \\
\hline$\tilde{6}$ & $\begin{array}{c}\text { Strongly very } \\
\text { strong importance }\end{array}$ & $(4,6,8)$ & $(1 / 8,1 / 6,1 / 4)$ \\
\hline$\tilde{7}$ & $\begin{array}{c}\text { Very strong } \\
\text { importance (VSI) }\end{array}$ & $(5,7,9)$ & $(1 / 9,1 / 7,1 / 5)$ \\
\hline$\tilde{8}$ & $\begin{array}{c}\text { Very strongly } \\
\text { extreme importance }\end{array}$ & $(6,8,9)$ & $(1 / 9,1 / 8,1 / 6)$ \\
\hline$\tilde{9}$ & Extreme importance (EXI) & $(7,9,9)$ & $(1 / 9,1 / 9,1 / 7)$ \\
\hline
\end{tabular}


Table 4. Linguistic values for causal relationships.

\begin{tabular}{cc}
\hline Linguistic values & TFN \\
\hline Extremely low (EL) & $(0,0.1,0.2)$ \\
Very low (VL) & $(0.1,0.2,0.3)$ \\
Low (L) & $(0.2,0.3,0.4)$ \\
Medium low (ML) & $(0.3,0.4,0.5)$ \\
Medium (M) & $(0.4,0.5,0.6)$ \\
Medium high (MH) & $(0.5,0.6,0.7)$ \\
High (H) & $(0.6,0.7,0.8)$ \\
Very high (VH) & $(0.7,0.8,0.9)$ \\
Extremely high (EH) & $(0.8,0.9,1)$ \\
\hline
\end{tabular}

From all the above, this paper has two specific aspirations. The first is theoretical, by considering the suitability and the capability as different purposes contrarily to most studies, for instance [6] [16] [17] [18] [39] and [40], while integrating the sustainability to bring out another approach than the ones of [59] [60]. The second is most technical, by targeting the best methods combination to embody the said three theoretical considerations in the same GIS analysis, as tried by [59] and [60].

\subsection{Study Area Preceding Methods Implementation}

The study area is the district of Njimom, located between latitudes North $5^{\circ} 40^{\prime}-6^{\circ}$ and East $10^{\circ} 48^{\prime}-11^{\circ} 20^{\prime}$, in the Noun Division and the Cameroon West Region (Figure 4). It covers an area of $780 \mathrm{~km}^{2}$, at the heart of transitional highlands between the southern and the northern Cameroon that are contrasted in climate and biophysical features. An average temperature of $25^{\circ} \mathrm{C}$ elsius and 1200 to $2000 \mathrm{~mm}$ of rainfall characterize its annual climate. The vegetation is mixt between sparse forests islands, grasslands and shrubs. The elevation is between 650 and 1533, and the culminant point is the Mount Yawou. Soils are volcanic less evolved, and depending on the elevation, they are dark red unstable on slopesor moist clay close to rivers. An important network of small rivers constitutes the hydrography and the main river is the Megna. The road network is mainly of rural type, and the national road $n^{\circ} 6$ open-up the district to the north of country. Economic activities are mainly agriculture, hunt, and commercials.

\subsection{Conditions-Layers Generation, Ranking and Grouping}

The layers were produced according to the standards scales (see Table 2), as well as investors' needs and the study area specificities. The main data are from raster and vector types. The Landsat 8 satellite image OLI-TIRS, of path and row coordinates 186-56, dated from the 27 January 2018 and covering the study area was downloaded from the official website of United States Geological Survey (USGS) at http://earthexplorer.usgs.gov/ (Table 5). 


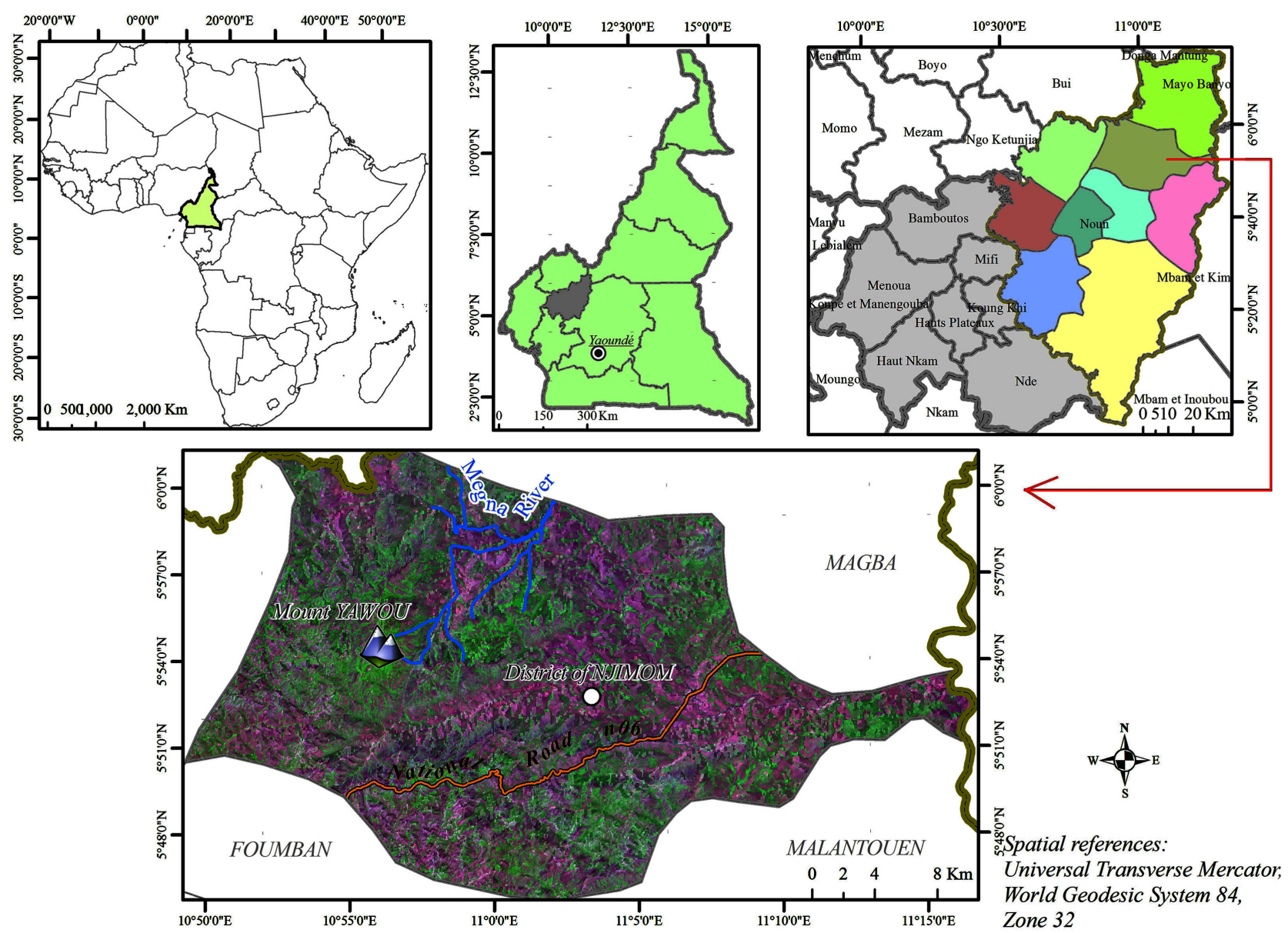

Figure 4. The study location.

Table 5. Landsat 8 scene metadata.

\begin{tabular}{cccc}
\hline Scene ID & Spectral Band & $\begin{array}{c}\text { Wavelength } \\
(\mu \mathrm{m})\end{array}$ & $\begin{array}{c}\text { Spatial } \\
\text { Resolution }(\mathrm{m})\end{array}$ \\
\hline & Aerosol/Coastal & $0.433-0.453$ & 30 \\
LC81860562018027LGN000 & Blue & $0.450-0.515$ & 30 \\
& Green & $0.525-0.600$ & 30 \\
& Red & $0.630-0.680$ & 30 \\
& Near Infrared & $0.845-0.885$ & 30 \\
& Short Wavelength Infrared & $1.560-1.660$ & 30 \\
& Short Wavelength Infrared & $2.100-2.300$ & 30 \\
& Panchromatic & $0.500-0.680$ & 15 \\
\hline
\end{tabular}

As all product of level 1 that is raw, the image need some preprocessing. Bands blue (B2) to short wavelength Infrared (B7) used in this study were stacked. Then, radiometric calibration from 16 bit to 8 bit and atmospheric corrections were performed. After, to enhance the spatial resolution, the panchromatic band (B8) was preprocessed and merged to the multispectral stacked image. 
The same way, the Shuttle Radar Terrain Model (SRTM) Digital Elevation Model (DEM), also available on the USGS website was downloaded and conditioned to fulfill the analysis requirements. With these two sets of data and the available vectors, the analysis could be conducted. The software used is Arcgis 10.4.1, Erdas Imagine 2015 and Super Decision Software (SDS) version 3.0.

- Temperatures and rainfall - Some sparse data, available at the local office of agriculture, were collected and completed by direct recordings of temperatures on the field every 300 or 500 meters. They vary between 22 and 27 degree Celsius during the year 2018. For the rainfall, a map of the study area was printed and the data of surrounding districts that are equipped with meteorological stations were used to approximate local yearly precipitations, with the help of the agriculture office. Then, based on the data of Foumban (South), Massangam (South-East), Magba (North-East) and Bamenda (North-West), Njimom district has been divided into four yearly rainfall areas inside the interval $1206 \mathrm{~mm}$ and $2145 \mathrm{~mm}$ (Figure 5). Both data were rasterized using the point density operation.

- Altitude, slope and sunshine - These three set of data were produced by using the conditioned DEM-SRTM. The desired elevation was obtained by applying a threshold. The slope was produced in degree and a threshold was applied. For the sunshine, the area solar radiation was performed. In ArcGIS software, it consists in deriving the incoming solar radiation from a raster surface. The interval requested was 365 days for the year 2018, the unit is watt-hours per square meter $\left(\mathrm{W} \cdot \mathrm{H} / \mathrm{m}^{2}\right)$, while the latitude helps for the accuracy of solar inclination and solar position.

- Forest cover - This layer was produced by combining three spectral indices commonly used in the Forest Canopy Density (FCD) model [61].

- Advanced Vegetation Index (AVI), that uses the power degree of the infrared response to highlight subtle differences in canopy density. (Equation (5))

$$
A V I=\sqrt[3]{((B 5+1) *(256-B 4) *(B 5-B 4))}
$$

- Canopy Shadow Index or Scaled Shadow Index (SI, SSI), which opposes forest stands and open area spectral axes. (Equation (6))

$$
S I=\sqrt{(256-B 3) *(256-B 4)}
$$

- Bare soil Index (BI), enhancing the bare soil areas, fallow lands, vegetation with marked background, in opposition to AVI. (Equation (7))

$$
B I=\frac{(B 5+B 3)-B 4}{(B 5+B 3)+B 4}
$$

In the raster calculator, the sum of AVI and SI was computed to enhance the sensing of forest mark. Then, the BI was subtracted from that new layer to minimize the soil effects.

- Soils quality - Two neo-bands were produced. To assess the soils richness, three indices taken from [62] and [63] were calculated following Equations 
(8), (9) and (10).

Clay Minerals $C M=B 6 / B 7$

Soil Composition Index $S C I=\frac{(B 6-B 5)}{(B 6+B 5)}$

Organic Matter Index $O M I=1 / B 3^{2}$

The three layers were stacked, a principal component analysis (PCA) was performed to extract the best of all information, and the component most related respectively to the $\mathrm{CM}, \mathrm{SCI}$ and $\mathrm{OMI}$, was retained as the best expression of the soil richness.
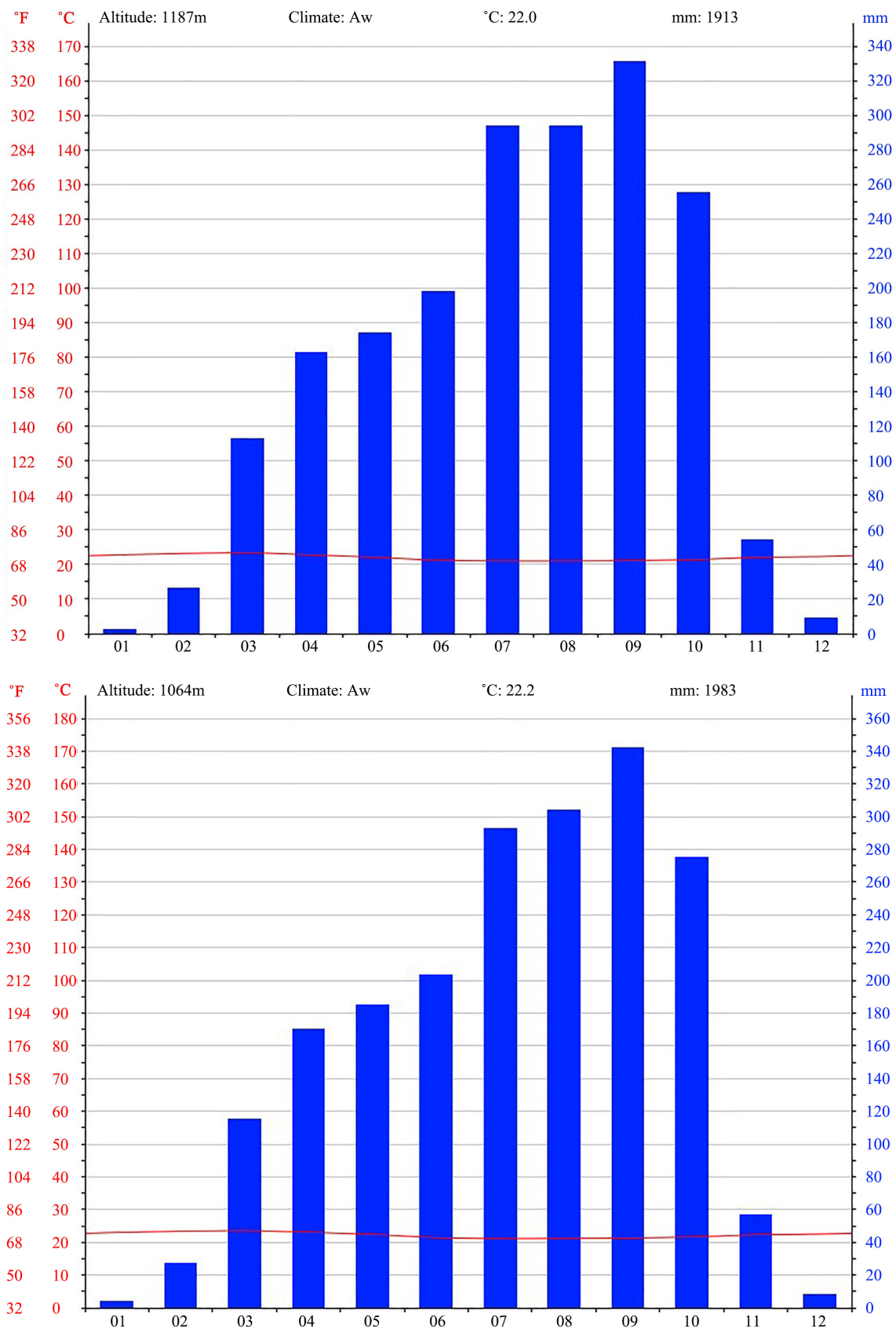

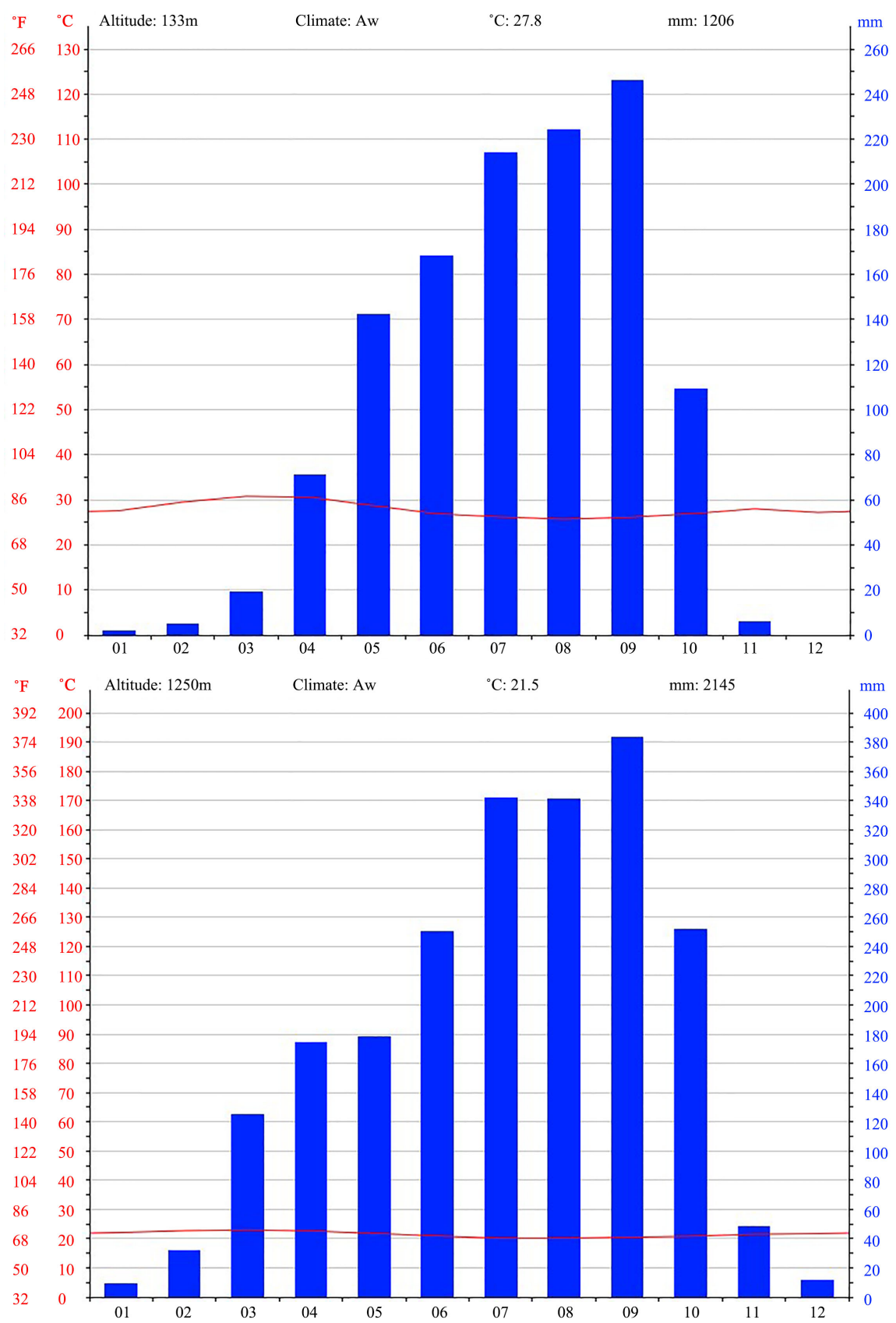

Figure 5. 2018 Rainfall diagrams and temperatures curves of Foumban, Massangam, Magba and Bamenda.

In the same logic, the soil moisture was assessed by first calculating the Land Water Surface Index (LWSI) following Equation (11).

$$
L W S I=B 5-B 6 / B 5+B 6
$$

Then, the stream network was digitized. A focal statistics analysis following a radius neighborhood of 20 meters was performed. To finish with this step, the drainage density of the study area was calculated according to Equation (12).

$$
D D=\text { Stream network length }(\mathrm{km}) / \text { Study Area }\left(\mathrm{km}^{2}\right)
$$


Considering that soils should be well-drained to enable well-fixed roots, but not permanently drained to jeopardize growing and harvesting [11], the LWSI and DD layers were integrated in a raster calculator and respectively weighted at $2 / 3(67 \%)$ and $1 / 3(33 \%)$, to obtain the soil moisture.

- Built-up - Some studies have shown that built-up indices give more accurate information than the supervised or unsupervised classification [64]. For instance, the Dry Built-up Index (DBI) recently developed was important in highlighting cities features in dry climates [65]. Its formula is given by Equation (13).

$$
D B I=(B 2-B 10 / B 2+B 10)-N D V I
$$

With NDVI meaning the Normalized Difference Vegetation Index, and expressed following the Equation (14).

$$
N D V I=(B 5-B 4 / B 5+B 4)
$$

However, the study area is not exactly a dry one with sands and dunes soils and a sparse steppe vegetation, but natural features as shrubs and grasslands, dark red unstable and wet soils depending on the elevation [65], while dozens of houses are built with raw materials as mud brick and straw, dominate it. These conditions have introduced some confusions and pixels reflectance inversion when the results were compared with the supervised classification and the vegetation indices as AVI and NDVI. Then, the inversion of the ratio term in the initial formula was experimented as shown in Equation (15) to obtain the expected results, which is built-up extraction:

$$
I D B I=(B 10-B 2 / B 10+B 2)-N D V I
$$

Based on the values threshold, the result was coded in two classes of suitability, 1 and unsuitability, 0 .

- Roads network - Assuming that the design of a modern oil palm plantation request the proximity of a factory for beneficial transformation [11], the easy transport of the products need a furnished road network. The study area is opened up thanks to rural tracks and the national road 6 (see Figure 1) and it was stated that the farm factory should be close to the road by $1 \mathrm{~km}$. The road network was digitized and rasterized using the Euclidian distance function on $4000 \mathrm{~m}$, to cover the whole study area. A threshold of $1000 \mathrm{~m}$ was then applied and recoded in two classes of suitability, 1 inside this distance, and unsuitability, 0 that is over this distance.

- Rivers - The aim was to conserve the current position of local palm oil prefabrication units and others artisanal mills. For this purpose, on a printed map laid out with spatial markers as rivers and hills, manual cognitive maps have been drawn all over the area with populations following the Participatory GIS (PGIS) approach proposed by [66], and geographic coordinates of eleven units have been recorded with a GPS. A raster image was created using the Euclidian distance function on $1500 \mathrm{~m}$ to cover the study area. A threshold of 
$100 \mathrm{~m}$ was applied to the resulting raster as the restricted perimeter to the rivers according to the population request. The binary image has 1 as suitable for the mills conservation over this distance, and 0 as unsuitable that equals to less than $100 \mathrm{~m}$.

Technically, the layers were assembled in natural capability and social-economical suitability. On one hand, the group of layers belonging to the natural capability were reclassified, and recoded on an appreciation scale of 0 to 5 denoting the lowest to the highest capability; and because they are fixed conditions or less flexible for the productivity, the layers were crossed following the straightforward method of WLC sum method, to obtain the "Capability layer". On the other hand, the social-economicalconditions-layers were aggregated after performing the AHP process. The pairwise comparison matrix has been built stating that local mills around the river network are 3 times less important than modern factory, but 5 times more than the built-up; while nearness between network road and modern factory importance is the highest, that is respectively 3 times and 7 times more than local mills and built-up (Equation (16)).

$$
\begin{gathered}
\text { River network } \\
\text { Road network } \\
\text { Built-up }
\end{gathered}\left[\begin{array}{ccc}
1 & 1 / 3 & 5 \\
3 & 1 & 7 \\
1 / 5 & 1 / 7 & 1
\end{array}\right]
$$

These relative weighs were normalized to obtain the priority vector. The consistency of judgments were assessed through ratio of the consistency index (CI) to the random index (RI) in Equation (17)

$$
C R=(C I / R I)<0.10
$$

The "Suitability layer" had resulted from sum of these three components weighted by their consistent priority vector in a raster calculator. The visual patterns and numerical results were confirmed by submitting the output image to the linear fuzzy membership operation.

Once the "Capability layer" and the "Suitability layer" were produced, it was important to assess the level of considering sustainability. The first step has consisted in counting the number of occurrences of the social, economic or environmental dimension in each layer processing (Table 6). Then after, the utility function was applied to come up with their individual sustainability values.

In both cases, $x_{1}, x_{2}$ and $x_{3}$ refer respectively to social, economic and environmental aspects of the sustainability. Inside each group of layers, the ratio has been made between each aspect number of occurrences and the total. Thus, the cube root of all results was computed, and the new values were multiplied to find the sustainability utility coefficient (SUC) for each group. The non-occurring or null values were computed as 1 .

As last step, in a raster calculator, each layer was multiplied by its so-called sustainability utility coefficient (SUC), before performing their weighted sum.

The diagram flowchart presented in Figure 6 synthesizes the main steps of the methodology. 
Table 6. Sustainability aspects occurrences relatedly to primary goals.

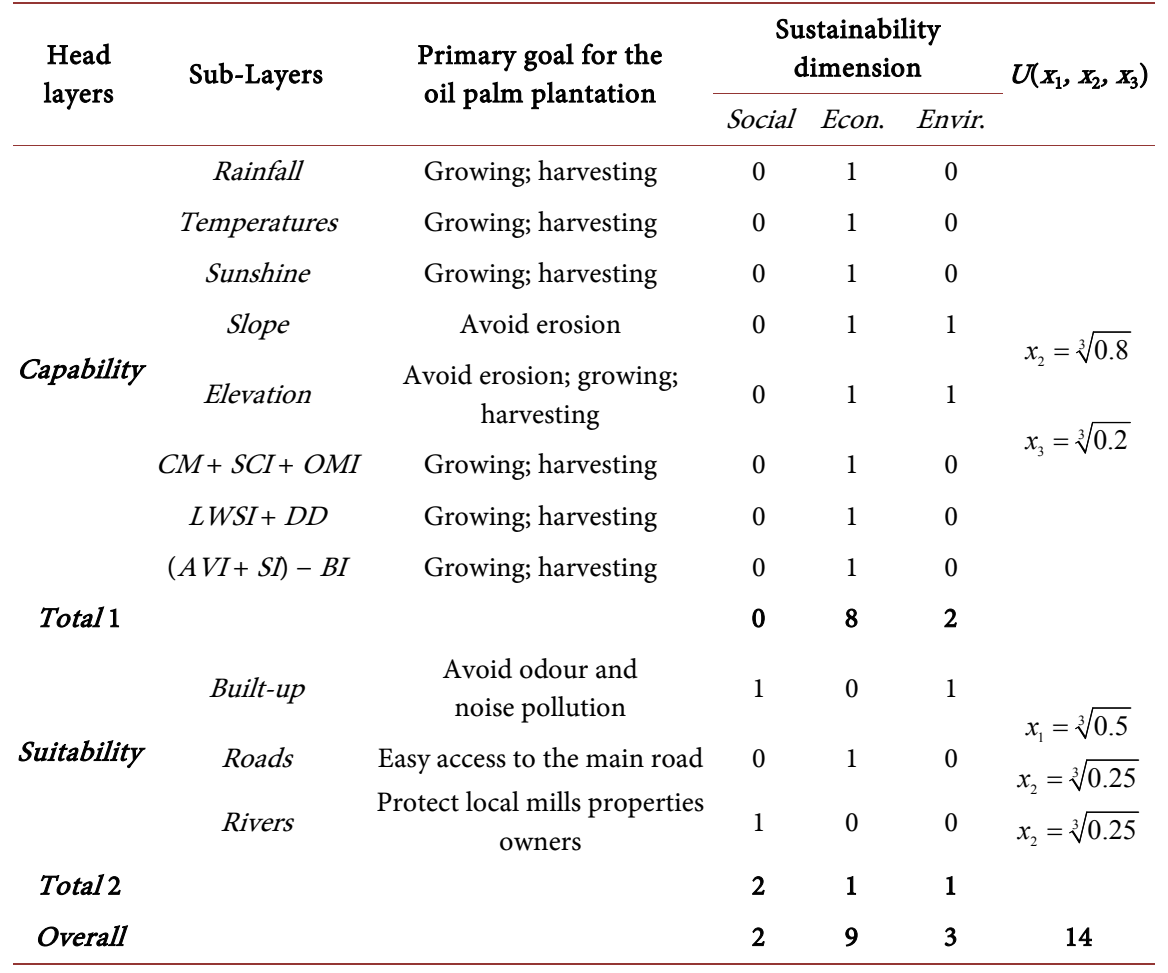

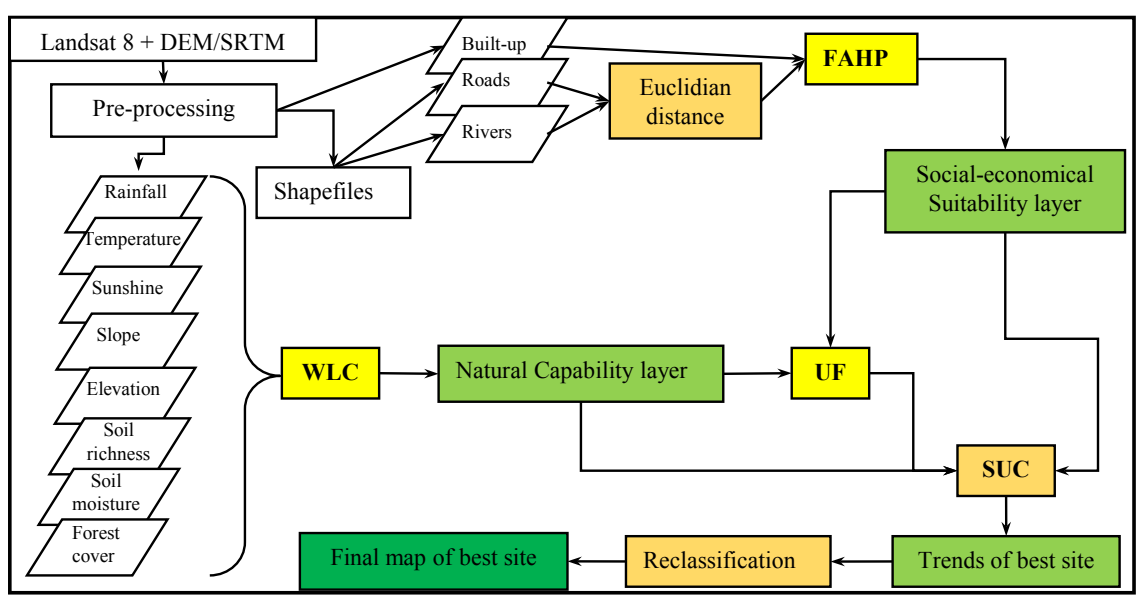

Figure 6. Methodology flowchart.

\section{Results}

\subsection{Conditions-Layers Raw Values and Classes}

An overall of eleven individual conditions-layers maps result from the processing above. Eight of them belong to the natural capability and three to the social-economical suitability for the oil palm planting. Inside the two groups, there are non-composed and composed or neo-bands layers.

For the natural capability, the non-composed layers are rainfall (1206 - 2145 $\mathrm{mm})$, temperatures $\left(20.2^{\circ} \mathrm{C}-27^{\circ}\right.$ Celsius $)$, sunshine $(13.58-2103508)$, slope $\left(0^{\circ}\right.$ $5.41^{\circ}$ ) and elevation (696 - $1533 \mathrm{~m}$ ) (Figure 7). They give the real conditions 
values for oil palm growing approximately around the ones indicated [11]. The composed or neo-band layers, as soil richness $(-0.0618-0.00015)$, soil moisture (3 - 12) and forest cover (0.67 - 258.7) (Figure 7). They are approximation of real conditions, by combining different simulation.
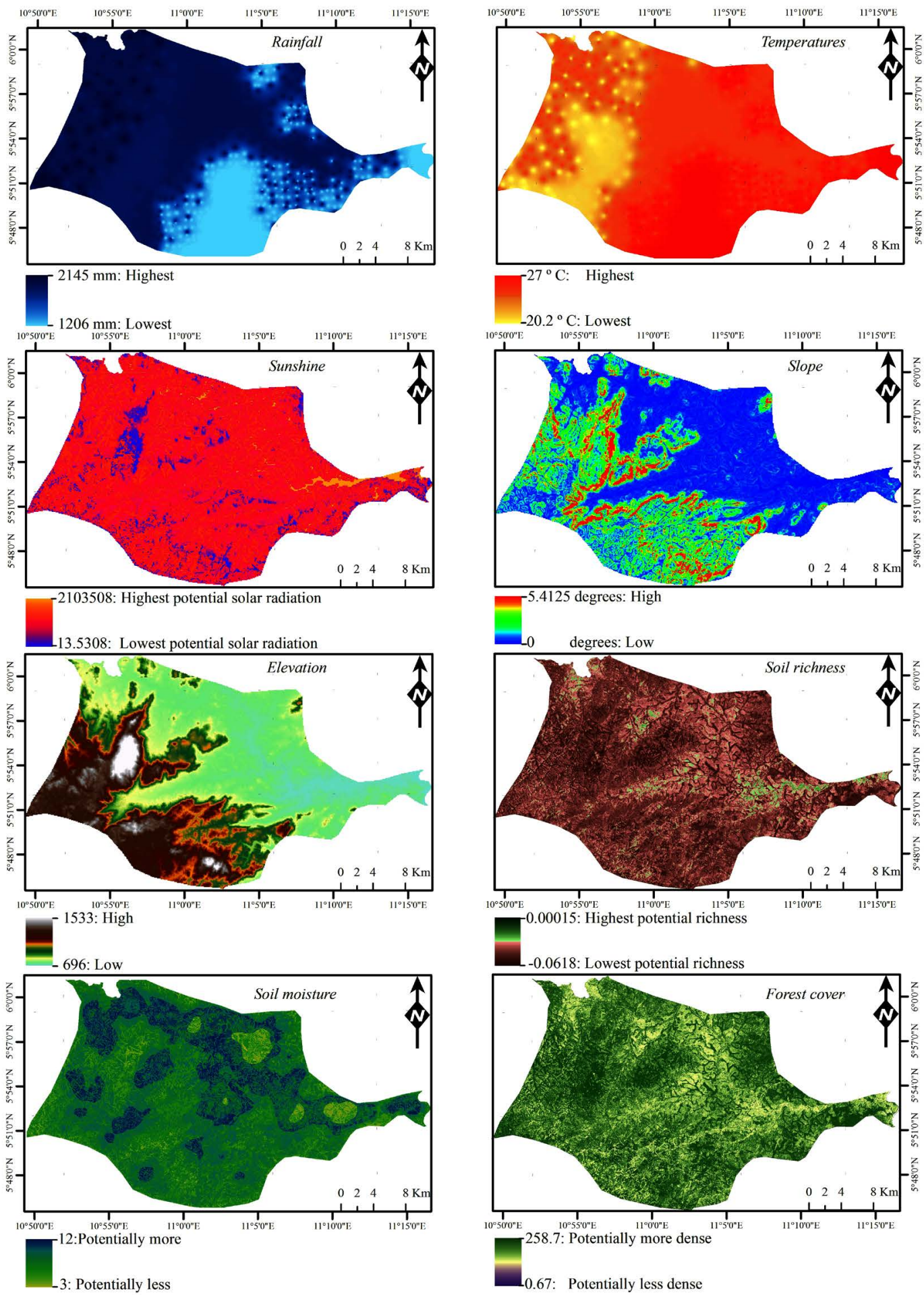

Spatial references: Universal Transverse Mercator, World Geodesic System 84,Zone 32

Figure 7. Natural capability conditions-layers. 


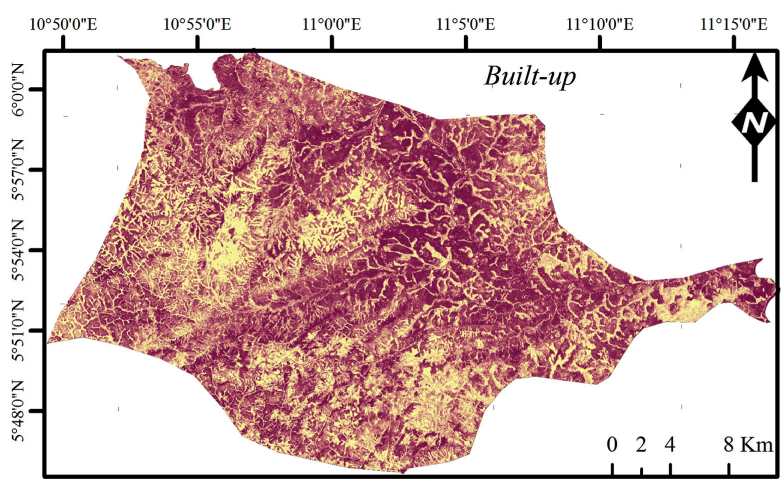

1.477: Potentially more present

Concerning the social-economical suitability, the non-composed layers are the distance to the road network $(0-3837 \mathrm{~m})$ and to the rivers $(0-1500)$ (Figure 8). They express the investors' needs and the population perception. The only composed layer is the built-up map $(-1.37$ - 1.477), whose values approximate the area to be avoid by the plantation (Figure 8 ).

When compared to the standards of oil palm farming [11], these conditions are generally averagely meet (see Table 2) for oil palm plantation in the area. Only the elevation (696 - $1533 \mathrm{~m}$ ), that should better be between 400 and $500 \mathrm{~m}$, as well as the soils that the best mineral content is clay, show some first view restrictions (see Table 2). Then, as stated above, the best way to assess that was the recoding of the layers according to the standardized scale.

The natural capability conditions-layers are reclassified into six new classes. The fuzzy linguistic scale is decreasing, with "Highest", "High", "Moderate", "Marginal", "Low", and "Lowest" capability. On the base of their original processed data, all the conditions-layers highest to lowest values were completely integrate the model, except the elevation whom data ranking were inverted, giving highest scores and qualifiers to the lowest altitudes. For the layers that extremes data were inexistent, the number of classes was adapted to the score values, for better results (Table 7, Figure 9).
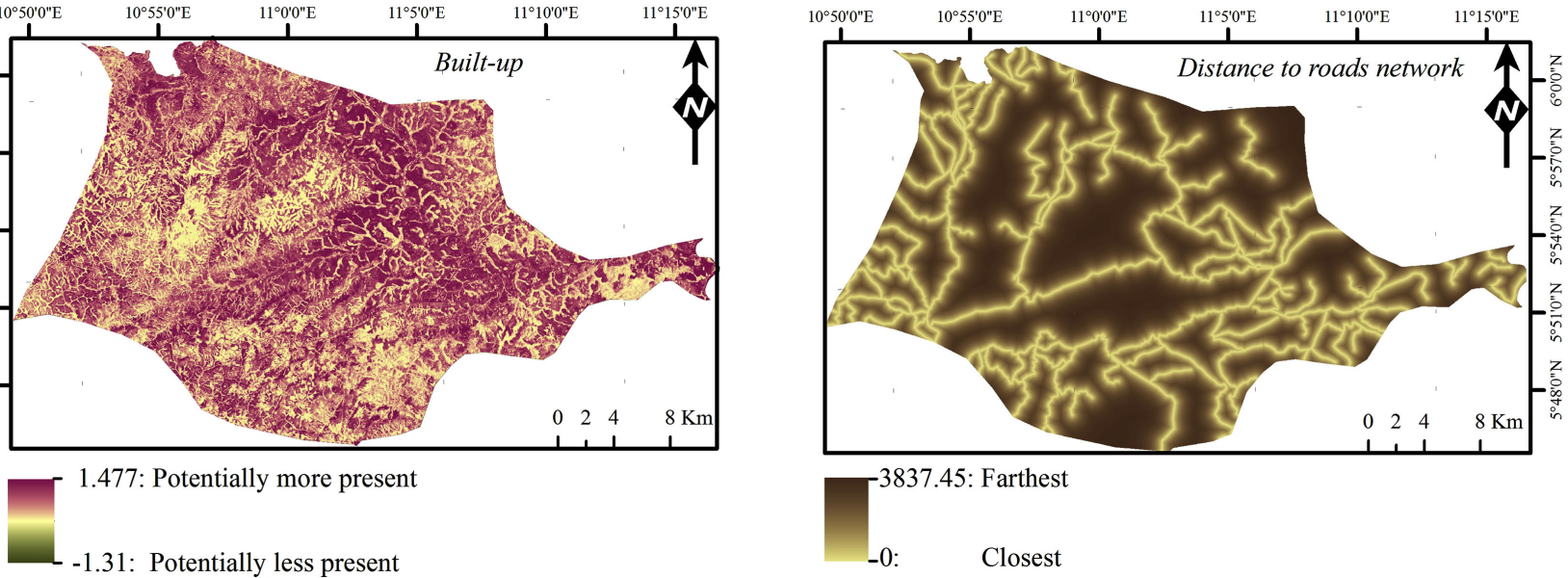

-3837.45: Farthest

Closest

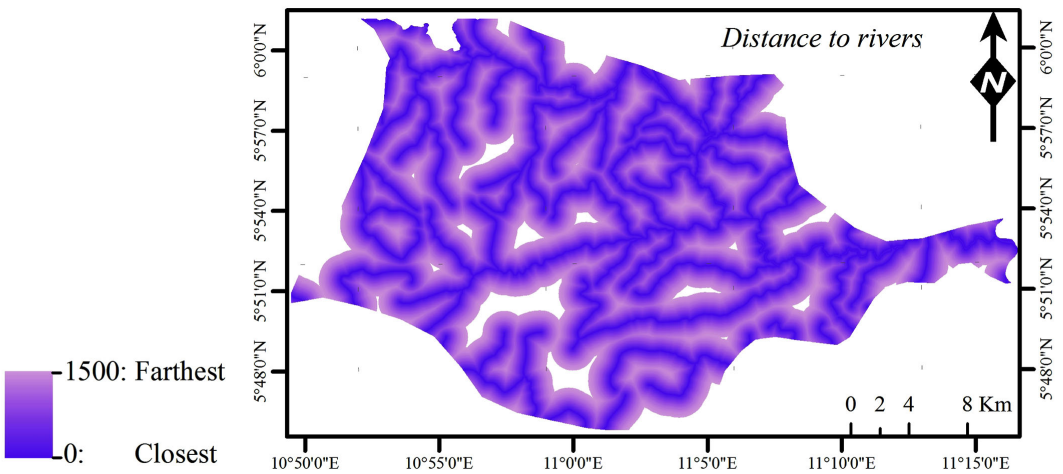

Spatial references: Universal Transverse Mercator, World Geodesic System 84,Zone 32

Figure 8. Social-economical suitability conditions-layers. 

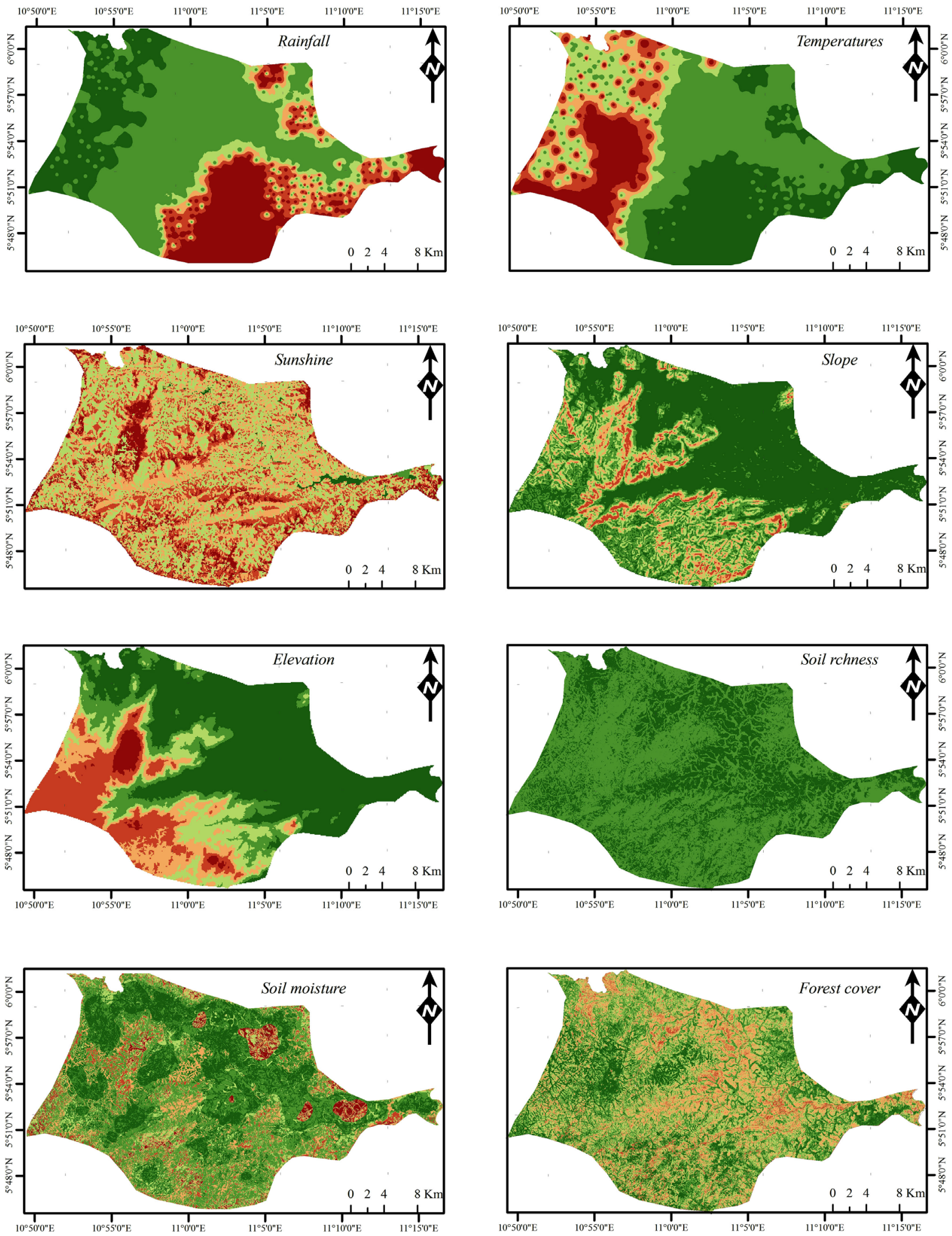

Capability class

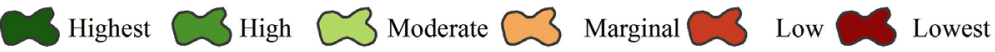

Spatial references: Universal Transverse Mercator, World Geodesic System 84,Zone 32

Figure 9. Natural capability conditions-layers reclassified. 
Table 7. Capability conditions-layers reclassification.

\begin{tabular}{|c|c|c|c|c|c|c|}
\hline \multirow{2}{*}{ Layer } & \multicolumn{5}{|c|}{ Capability scores } & \multirow[b]{2}{*}{0} \\
\hline & 5 & 4 & 3 & 2 & 1 & \\
\hline Rainfall & 2145 & Normal Breaks & Normal Breaks & Normal Breaks & Normal Breaks & 1026 \\
\hline Temperatures & 27 & Normal Breaks & Normal Breaks & Normal Breaks & 20.2 & N/A \\
\hline Sunshine & $2,103,508$ & Normal Breaks & Normal Breaks & Normal Breaks & Normal Breaks & 13.5308 \\
\hline Slope & N/A & 5.41 & Normal Breaks & Normal Breaks & Normal Breaks & 0 \\
\hline Elevation & N/A & $696-850$ & $850-1050$ & $1050-1280$ & $1280-1500$ & 1533 \\
\hline Soil richness & 0.00015 & Normal Breaks & Normal Breaks & Normal Breaks & Normal Breaks & -0.01618 \\
\hline Soil moisture & 12 & Normal Breaks & Normal Breaks & Normal Breaks & Normal Breaks & 3 \\
\hline Forest cover & 258.7 & Normal Breaks & Normal Breaks & Normal Breaks & Normal Breaks & 0.67 \\
\hline
\end{tabular}

The social-economical suitability conditions-layers have two classes, "Suitable" and "Unsuitable". The highest values of the built-up are unsuitable for the oil plantation. The distance of $4000 \mathrm{~m}$ around the road is the suitable for the factory for the easy access. The distance over $100 \mathrm{~m}$ of the river is suitable for the farming and the factory to preserve local oil palm production activity and then avoid conflicts with local population (Table 8, Figure 10).

\subsection{Capability and Social-Economical Combined Layers}

The capability layer is resulting from the WLC shows trends with values going from 23 to 45 . The highest capability is recorded in the northern part of the study area. Its scores correspond to highest soil richness, soil moisture and forest cover, average sunshine, rainfall and temperatures, lowest altitude and slope (Figure 11).

The suitability layer is the result of the AHP performing (Table 9).

Then, the three recoded layers multiplied by their priority vectors are respectively, the river network layer by 0.2828 , the road network layer by 0.6434 and the built-up layer by 0.0738 . Their linear fuzzy membership sum is in the interval between 0 and 1 , with a visible domination of the road network layer (Figure $11)$.

\subsection{Sustainability Utility Coefficients (SUC) Weighing and Final Best Site Maps}

Following the UF computing, each layer obtains a SUC rated on a fuzzy scale of 0 to 1 . None of both groups fulfils the sustainability dimensions at $100 \%$. Natural capability processing express it at $54.2 \%$, that is normalised value of 0.542 , while social-economical processing express it at $31.5 \%$, that is a normalised value of 0.315 (Table 10).

The two layers are recoded into six classes for the final map scale of appreciation. Then, using the SUC normalized values, the capability layer is multiply by 0.542 and the suitability layer by 0.315 . The sum of two layers in the raster calculator had given the last map. 

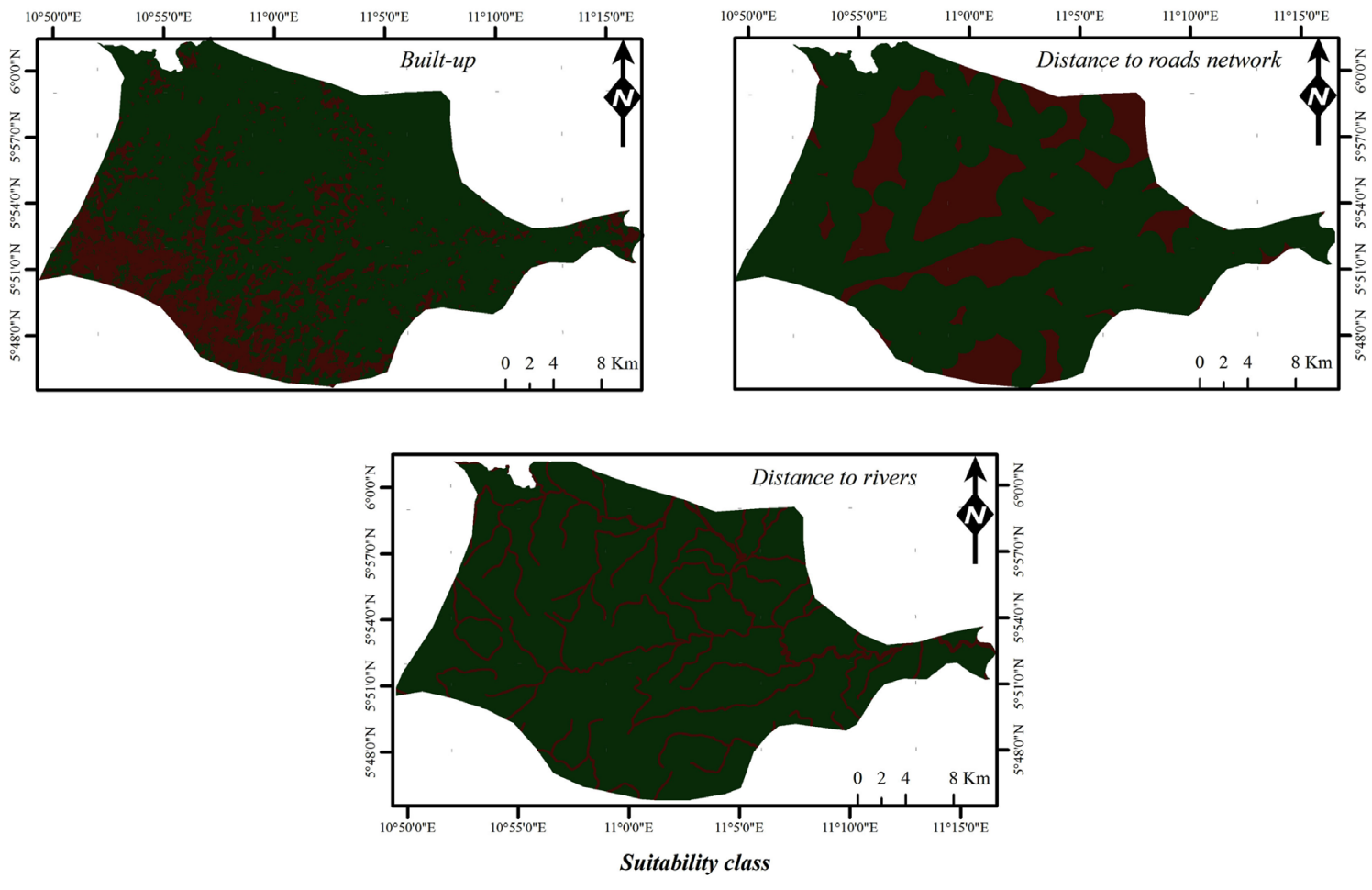

3 Suitable

3 Unsuitable

Spatial references: Universal Transverse Mercator, World Geodesic System 84,Zone 32

Figure 10. Social-economical suitability conditions-layers reclassified.
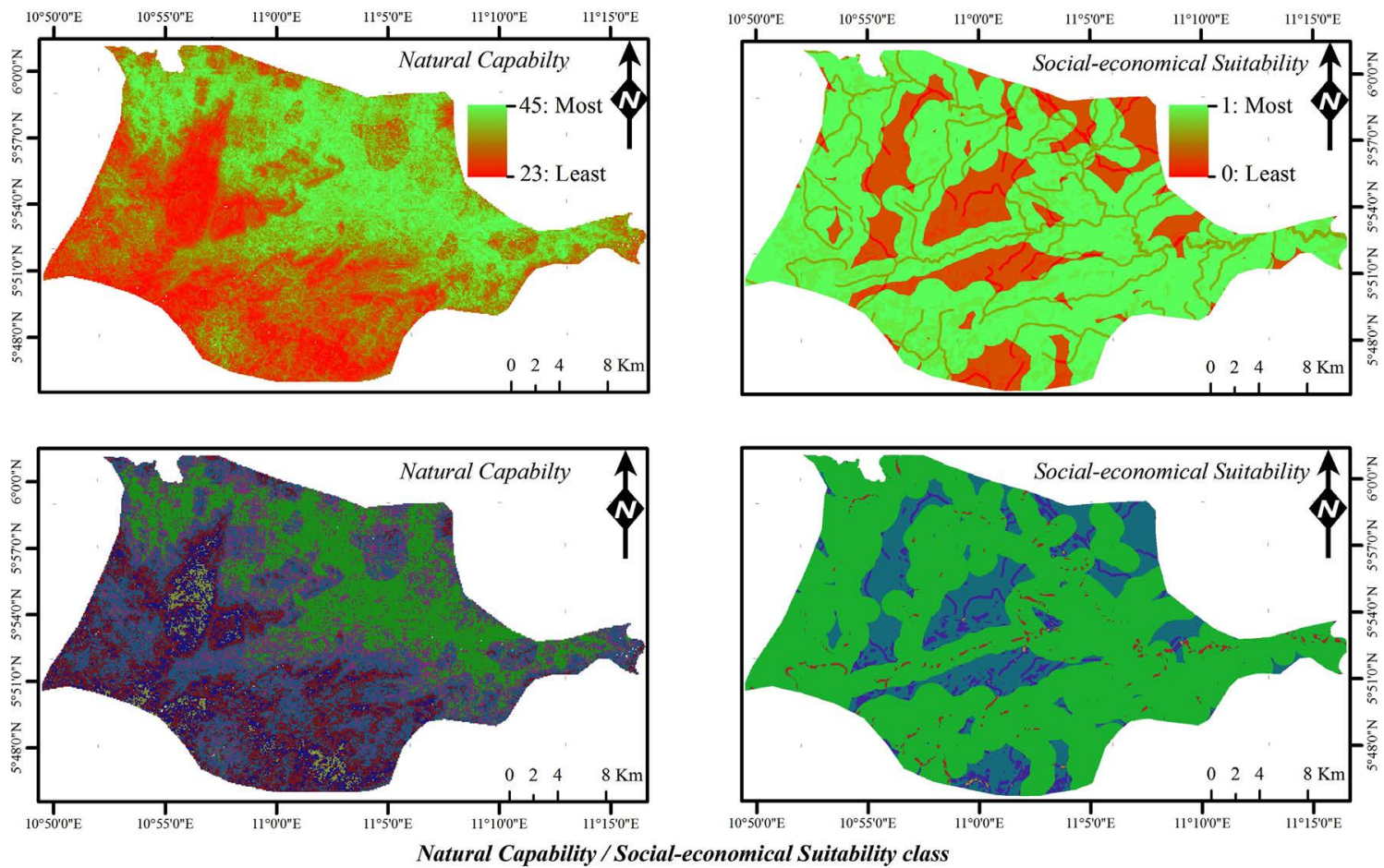

3 Highest

High

0 Moderate

3 Marginal

Low $\sim$ Lowest

Spatial references: Universal Transverse Mercator, World Geodesic System 84,Zone 32

Figure 11.Capability and Suitability maps combined and reclassified. 
Table 8. Suitability conditions-layers reclassification.

\begin{tabular}{ccc}
\hline & \multicolumn{2}{c}{ Suitability scores } \\
\cline { 2 - 3 } Layers & 1 & 0 \\
\hline Built-up & $-1.31-0.673$ & $0.673-1.477$ \\
Distance to road (m) & $\leq 4000$ & $>4000$ \\
Distance rivers (m) & $>100$ & $\leq 100$ \\
\hline
\end{tabular}

Table 9. AHP matrix priority vectors.

River network
Road network
Built-up $\left[\begin{array}{ccc}1 & 1 / 3 & 5 \\ 3 & 1 & 7 \\ 1 / 5 & 1 / 7 & 1\end{array}\right] \quad\left[\begin{array}{l}0.2828 \\ 0.6434 \\ 0.0738\end{array}\right]$

Table 10. Sustainability utility coefficients (SUC) of head-layers.

\begin{tabular}{ccccc}
\hline & \multicolumn{3}{c}{ Sustainability dimensions } & \\
\cline { 2 - 4 } & $\boldsymbol{x}_{1}$ & $\boldsymbol{x}_{\mathbf{2}}$ & $\boldsymbol{x}_{\mathbf{3}}$ & \\
\hline Capability & $/ /$ & 0.928 & 0.584 & 0.542 \\
Suitability & 0.793 & 0.63 & 0.63 & 0.315 \\
Overall & & & & $\mathbf{0 . 8 5 7}$ \\
\hline
\end{tabular}

The final map is laid out in four different designs (Figure 12). The first one shows the main trends from the best to the least or worst conditions. The values are comprised between 5.142 in the best case and 0.857 in the worst. The main area for the high values is in the north of Njimom district. This map is recoded into six classes to discriminate and prioritize the sites in the second map. The ranking is from the first to the sixth priority for the investor, with areas comprised between 35,700 ha and 153 ha (Figure 13). When applying a binary recoding following the "Yes" $/$ "No" logic to this map, considering the highest class as valid and others as invalid, its enables to highlighting the best site of the study area in the third map. The first priority area is the best site, on an area of 35,700 ha. Ten plantations over eleven related to the local mills used for the analysis are within the limits of the site. The sum of their estimated minimum areas, when taking seize as 7.5 ha according to [11] for small farmers $(7.5 \times 10=750)$ (see Table 2), is subtracted from this 35,700 ha, and the approximate overall exploitable area is about $34,950 \mathrm{ha}$; that is $44.8 \%$ of the $78,000 \mathrm{ha}\left(780 \mathrm{~km}^{2}\right)$ district total area (Figure 14). The selected site is then utilisable for the large size modern oil palm plantation (See Table 2). At last, the limit of the best site is drawn, and the most central position of the polygon is chosen to locate and install the modern factory inside the planting area and relatedly to the eleven local mills recorded in the district. 

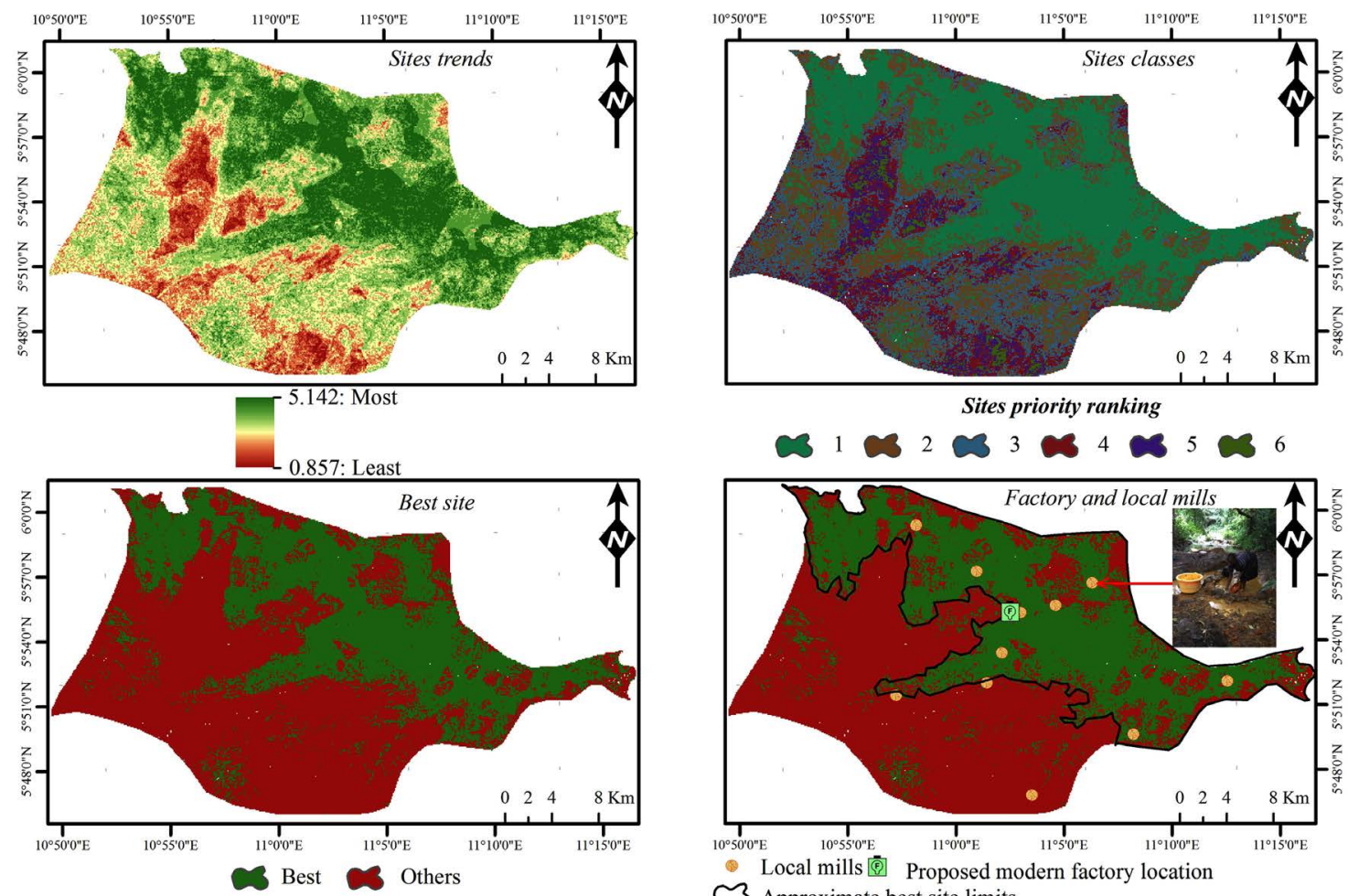

3 Approximate best site limits

Spatial references: Universal Transverse Mercator, World Geodesic System 84,Zone 32

Figure 12. The best site area.

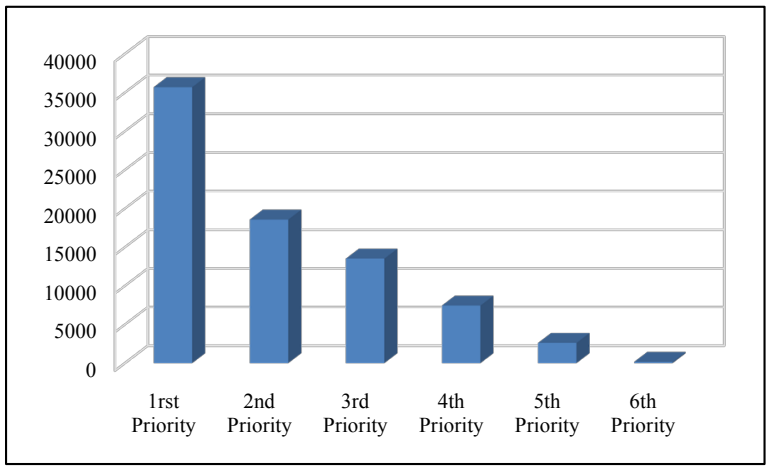

Figure 13. Six classes of priority areas in hectares.

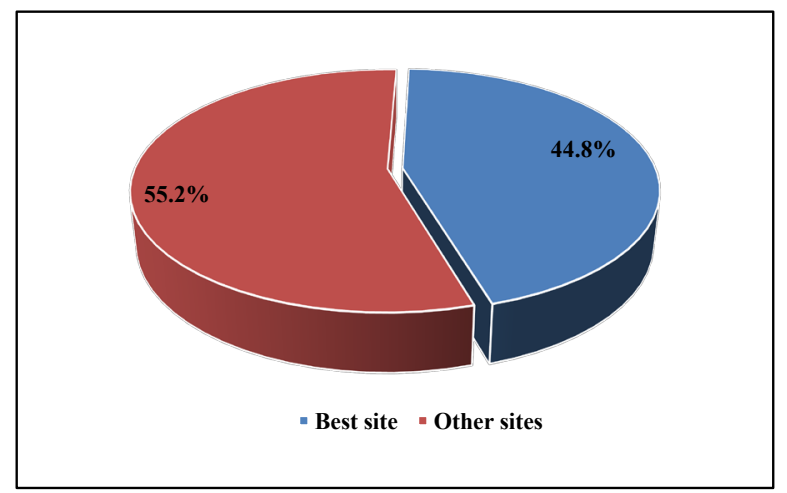

Figure 14. Ratio of the best site area over the others. 


\section{Discussions and Outlook}

According to the main purpose of selecting the best oil palm planting site, this study has been done following as possible the international ranking standards. The main outcome of the processing locates the potentially most indicated site on the northern lowlands of Njimom district as shown in Figure 12. Its visual comparison with the inputs layers shows a large influence of the "Capability layer" trends (see Figure 11). One-step backward and still based on the visual comparison, seven on eight conditions-layers are highly highlighting the northern area as most favourable, except the forest cover layer that records the medium and lowest values there (see Figure 7 \& Figure 9); while layers as slope and elevation most clearly, but also rainfall and temperatures, deeply influence the shape of the chosen site.

Further, the main explanation of the "Capability layer" trends domination over the "Suitability layer" ones on the best site selection is the weighing process using the sustainability utility coefficients (SUC). Indeed, with respectively more than $50 \%(0.542)$ and just $30 \%(0.315)$, the outcome is more representative of the first layer than the second one. Consequently, when estimating the areas of the highest capability value (Figure 11) and the best site area, they are respectively 23,349 ha and 34,950 ha. The difference of 11,601 ha represents the contribution of the "Suitability layer" to the final selection, which is $33.2 \%$ or $1 / 3$ of the total area, versus $66.8 \%$ or $2 / 3$ represented by the above "Capability layer" value.

On another point, although the site is the most adequate according to the local available conditions, it does not meet 100\%, because the layers of slope and elevation do not record the highest ranking of 5 . Then the highest score ranking of the final map is at the most 4 according to the international standards.

The same way, concerning the purpose of erosion, the said standards and all the studies read on the purpose of oil palm land suitability most focus on avoiding any risk than integrating it to the modelling process. To pursue with this study, the main outlook is on one hand to build a complete model of the Revised Universal Soil Loss Equation (RUSLE) and integrate it to the model. On the other hand, integrating the status of the land degradation in the process, following the model proposed by [67] can bring more information to the site selection. These two components might reinforce or mitigate the outcome.

The analysis has also opened the way to apply the DBI to extract the built-up, and finally to test the inverse ratio of this formula for better results (see Equations (13) and (15)). This is a point the authors are already working on, to deepen the understanding of raw materials built-up reflectance parameters, related to thermal infrared and blue bands of the electromagnetic spectrum, in the remote sensing of diverse dry climates cities.

\section{Conclusion}

This paper has experimented to combine the WLC, FAHP and UF methods in the same GIS environment. The goal was to choose the best oil palm planting 
site. The three directions were capability and suitability, headed by the idea of sustainability. Then it appears that in the district of Njimom, with transitional biophysical features between the equatorial and the tropical climate, some requirements are fulfilled for oil palm planting in its northern side. Therefore, using the straightforward approach of WLC helps to follow the standardized scale of adequate conditions as rainfall, temperatures, sunshine, slope, elevation, soil richness and moisture, and forest cover, which should be respected for better growing and harvesting. The same way, using a flexible analysis as FAHP helps to integrate the human thoughts and choices in the analysis as built-up, factory location or local populations' mills. Another enhancement is the level of considering sustainability, 0.857 , that is further used as an evaluator of the overall social, economic and environmental dimensions of a plantation project. At last, combining the three methods has brought up the best site for oil palm plantation on an area of 34,950 ha, predisposing the district of Njimom to host modern and sustainable agriculture for local development.

\section{Acknowledgements}

Authors are thankful to the USGS program making available the satellite images for free downloading on their website. We are also grateful to our head of laboratories that brought their comments to improve the contents and the processing. At last, the help of the local office of agriculture experts and agents was the key contribution for a successful fieldwork, by organizing meetings with populations as well as leading/supporting the data collection.

\section{Conflicts of Interest}

The authors declare no conflicts of interest regarding the publication of this paper.

\section{References}

[1] Verheye, W. (2010) Growth and Production of Oil Palm. In: Verheye, W., Ed., Land Use, Land Cover and Soil Sciences. Encyclopedia of Life Support Systems (EOLSS), UNESCO-EOLSS Publishers, Oxford, UK, 1-24.

[2] Basiron, Y. (2007) Palm Oil Production through Sustainable Plantations. European Journal of Lipid Science and Technology, 109, 289-295. https://doi.org/10.1002/ejlt.200600223

[3] Hardter, R., Chow, W.Y. and Hock, O.S. (1997) Intensive \& Plantation Cropping, a Source of Sustainable Food Andenergy Production in Tropical Rain Forest Areas of Southeast Asia. Forest Ecology and Management, 91, 93-102.

[4] Carolita, I., Sitorus, J. and Rizqi Ianatus, S. (undated) Classification of Vegetation and Oil Palm Age Using SPOT6: The Case of Tana Laut South Kalimantan, Indonesia. $8 \mathrm{p}$.

[5] World Wildlife Fund. https://www.worldwildlife.org/publications/palm-oil-scorecard-2016

[6] Pirker, J. and Mosnier, A. (2015) Global Oil Palm Suitability Assessment. IIASA Interim Report. IR-15-006. http://pure.iiasa.ac.at/11682/

[7] Anderson, T. (2006) Oil Palm and Small Farmers in Papua New Guinea. 
https://np-net.pbworks.com/f/Anderson+(2006)+Oil+palm+and+small+farmers+in + PNG,+CELCR.pdf

[8] Corley, R.H.V. and Tinker, P.B. (2003) The Oil Palm. 4th Edition, Blackwell Publishing, Oxford, UK.

[9] Schmidt, J.H. and Weidema, B.P. (2008) Shift in the Marginal Supply of Vegetable Oil. International Journal of Life Cycle Assessment, 13, 235-239. https://doi.org/10.1065/lca2007.07.351

[10] OECD \& FAO (2013) Oilseeds and Oilseed Products. In: OECD-FAO Agricultural Outlook, OECD \& FAO, 139-159.

http://www.fao.org/fileadmin/templates/est/COMM_MARKETS_MONITORING/ Oilcrops/Documents/OECD_Reports/OECD_2013_22_oils_proj.pdf

[11] FAO. http://www.fao.org/docrep/006/t0309e/T0309E01.htm\#ch1

[12] Mielke (2000) Oil World Annual.

[13] Salunkie, D.K., Chavan, J.K., Adsule, R.N. and Kadam, S.S. (1992) World Oil Seeds: Chemistry, Technology and Utilization. Chapter 6, Van Nostrand Reinhold, New York, 217-248.

[14] Pirker, J., Mosnier, A., Kraxner, F., Havlík, P. and Obersteiner, M. (2016) What Are the Limits to Oil Palm Expansion? Global Environmental Change, 40, 73-81. https://doi.org/10.1016/j.gloenvcha.2016.06.007

[15] Qiu, F., Chastain, B., Zhou, Y., Zhang, C. and Sridharan, H. (2014) Modeling Land Suitability/Capability Using Fuzzy Evaluation. GeoJournal, 79, 167-182. https://doi.org/10.1007/s10708-013-9503-0

[16] Pirker, J. (undated) Oil Palm Suitability Map for South-West Cameroon. In: Mapping Oil Palm Suitability Protocol, Technical Annex 1, LTS International Technical Annex 1.

http://www.euredd.efi.int/documents/15552/317710/Protocol_Oil+Palm+Suitability .pdf/00b022b3-ad15-4654-a8cc-1ea3b2012c22

[17] Raschio, G., Alei, F. and Alkam, F. (2016) Draft Report on Future Deforestation Modeling and Land Suitability Assessment for Oil Palm. Agricultural Mapping Assessment in Papua New Guinea. Forest Carbon Partnership and UNDP.

[18] Aldababseh, A., Temimi, M., Maghelal, P., Branch, B. and Wulfmeyer, V. (2018) Multi-Criteria Evaluation of Irrigated Agriculture Suitability to Achieve Food Security in an Arid Environment. Sustainability, 10, 803. https://doi.org/10.3390/su10030803

[19] Kurtener, D., Torbert, H.A. and Krueger, E. (2008) Evaluation of Agricultural Land Suitability: Application of Fuzzy Indicators. In: Gervasi, O., Murgante, B., Laganà, A., Taniar, D., Mun, Y. and Gavrilova, M.L., Eds., Computational Science and Its Applications-ICCSA 2008, Lecture Notes in Computer Science, Vol. 5072, Springer, Berlin, Heidelberg, 475-490. https://doi.org/10.1007/978-3-540-69839-5_35

[20] Wahid, B.O., Nordiana, A.A. and Tarmizi, A.M. (2005) Satellite Mapping of Oil Palm Land Use. MPOB TT No. 255, 1-4.

[21] Harris, I., Mumford, C.L. and Naim, M.M. (2014) A Hybrid Multi-Objective Approach to Capacitated Facility Location with Flexible Store Allocation for Green Logistics Modeling. Transportation Research Part E: Logistics and Transportation Review, 66, 1-22. https://doi.org/10.1016/j.tre.2014.01.010

[22] McMorrow, J. (1995) Relation of Oil Palm Spectral Response to Stand Age. International Journal of Remote Sensing, 16, 3203-3209.

https://doi.org/10.1080/01431169508954624 
[23] Wahid, B.O. (1998) Discrimination of Oil Palm from Other Land Cover Types Using Remote Sensing Technique. Proceedings of the PORIM-Industry Forum.

[24] Lukman, F.M. and Poeloengan, Z. (1996) Application of Remote Sensing Technique for Oil Palm Plantation Management. Proceedings of the 1996 PORIM International Palm Oil Congress. Competitiveness for the 21 st Century, Hotel Istana, Kuala Lumpur, Malaysia, 23-28 September 1996, 460-467.

[25] Chemura, A., Van Duren, I. and van Leeuwen, L.M. (2015) Determination of the Age of Oil Palm from Crown Projection Area Detected from WorldView-2 Multispectral Remote Sensing Data: The Case of Ejisu-Juaben District, Ghana. ISPRS Journal of Photogrammetry and Remote Sensing, 100, 118-127. https://www.sciencedirect.com/science/article/abs/pii/S0924271614001968?via\%3Di $\underline{\text { hub }}$ https://doi.org/10.1016/j.isprsjprs.2014.07.013

[26] Fitrianto, A.C., Darmawan, A., Tokimatsu1, K. and Sufwandika, M. (2017) Estimating the Age of Oil Palm Trees Using Remote Sensing Technique. IOP Conference Series: Earth and Environmental Science, 148, Article ID: 012020.

[27] Fitrianto, A.C., Yuwono, D.M., Darmawan, A. and Tokimatsu, K. (2018) Determining Oil Palm Stands Age Using Multi Temporal Images Analysis. Environmental Sciences. https://doi.org/10.20944/preprints201810.0187.v1

[28] Li, L., Dong, J., Njeudeng Tenku, S. and Xiao, X. (2015) Mapping Oil Palm Plantations in Cameroon Using PALSAR 50-m Orthorectified Mosaic Images. Remote Sensing, 7, 1206-1224. https://doi.org/10.3390/rs70201206

[29] Mojaddadi Rizeei, H., Shafri, H.Z.M., Mohamoud, M.A., Pradhan, B. and Kalantar, B. (2018) Oil Palm Counting and Age Estimation from WorldView-3 Imagery and LiDAR Data Using an Integrated OBIA Height Model and Regression Analysis. Journal of Sensors, 2018, Article ID: 2536327. https://doi.org/10.1155/2018/2536327

[30] Okarda, B., Carolita, I., Kartika, T. and Komarudin, H. (2018) Mapping of Smallholder Oil Palm Plantation and Development of a Growth Model. IOP Conference Series: Earth and Environmental Science, 169, Article ID: 012074.

[31] Santos, C. and Messina, J.P. (2008) Multi-Sensor Data Fusion for Modeling African Palm in the Ecuadorian Amazon. Photogrammetric Engineering \& Remote Sensing, 74, 711-723. https://doi.org/10.14358/PERS.74.6.711

[32] Lu, D. (2006) The Potential and Challenge of Remote Sensing-Based Biomass Estimation. International Journal of Remote Sensing, 27, 1297-1328. https://doi.org/10.1080/01431160500486732

[33] Komba Mayossa, P.C. and Gadal, S. (2016) Monitoring Spatial Accuracy of Oil Palm Cultivation Mapping in Southern Cameroon from Landsat Series Images. Proceedings of Conference of Spatial Accuracy, Montpellier, France, July 2016, 358-365.

[34] Morel, A.C., Saatchi, S.S., Malhi, Y., Berry, N.J., Banin, L., Burslem, D., Nilus, R. and Ong, R.C. (2011) Estimating Aboveground Biomass in Forest and Oil Palm Plantation in Sabah, Malaysian Borneo Using ALOS PALSAR Data. Forest Ecology and Management, 262, 1786-1798. https://doi.org/10.1016/j.foreco.2011.07.008

[35] Ordway, E.M., Naylor, R.L., Nkongho, R.N. and Lambin, E.F. (2019) Oil Palm Expansion and Deforestation in Southwest Cameroon Associated with Proliferation of Informal Mills. Nature Communications, 10, Article No. 114. https://doi.org/10.1038/s41467-018-07915-2

[36] Komba Mayossa, P.C., Gadal, S. and Roda, J.M. (2017) Remote Sensing of Industrial 
Palm Groves in Cameroon. ASM Science Journal, Special No. 1, 16-45.

[37] Tan, K.P., Kanniah, K.D. and Cracknell, A.P. (2013) Use of UK-DMC 2 and ALOS PALSAR for Studying the Age of Oil Palm Trees in Southern Peninsular Malaysia. International Journal of Remote Sensing, 34, 7424-7446. https://doi.org/10.1080/01431161.2013.822601

[38] Loong Chong, K., Kanniah, K.D., Pohl, C. and Pang Tan, K. (2017) A Review of Remote Sensing Applications for Oil Palm Studies. Geo-Spatial Information Science, 20, 184-200. https://doi.org/10.1080/10095020.2017.1337317

[39] Eastman, J.R. (1999) Multi-Criteria Evaluation and GIS. University of Edinburg, G.B., UK, 493-502. https://www.geos.ed.ac.uk/ gisteac/gis_book_abridged/files/ch35.pdf

[40] Malczewski, J. (2006) GIS-Based Multi-Criteria Decision Analysis: A Survey of the Literature. International Journal of Geographical Information Science, 20, 703-726. https://www.tandfonline.com/doi/pdf/10.1080/13658810600661508

[41] McDowell, R.W., Snelder, T., Harris, S., Lilburne, L., Larned, S.T., Scarsbrook, M., Curtis, A., Holgate, B., Phillips, J. and Taylor, K. (2018) The Land Use Suitability Concept: Introduction and an Application of the Concept to Inform Sustainable Productivity within Environmental Constraints. Ecological Indicators, 91, 212-219. https://doi.org/10.1016/j.ecolind.2018.03.067

[42] Bizuwerk, A., Peden, D., Taddese, G. and Getahun, Y. (2005) GIS Application for analysis of Land Suitability and Determination of Grazing Pressure in Upland of the Awash River Basin, Ethiopia. International Livestock Research Institute (ILRI), Addis Ababa, Ethiopia.

[43] Corley, R.H.V. and Tinker, P.B. (2008) The Oil Palm. 4th Edition, Wiley-Blackwell, NJ.

[44] Yao, R. and Kamagate, D. (2010) Production du palmier à huile (Elaeis guineensis JACQ.) et taux d'extraction dans des conditions climatiques marginales au Nord-est de la Côte d'Ivoire. Agronomie Africaine, 22, 149-161.

[45] FAO (1976) A Framework for Land Evaluation. FAO Soils Bulletin, FAO, Rome, $1-79$.

[46] United States Department of Agriculture (1961).

[47] Al-Hanbali, A., Alsaaideh, B. and Kondoh, A. (2011) Using GIS-Based Weighted Linear Combination Analysis and Remote Sensing Techniques to Select Optimum Solid Waste Disposal Sites within Mafraq City, Jordan. Journal of Geographic Information System, 3, 267-278. https://doi.org/10.4236/jgis.2011.34023

[48] Eastman, J.R., Kyem, P.A.K., Toledano, J. and Jin, W. (1993) GIS and Decision Making. UNITAR, Geneva.

[49] Berry. J.K. (1993) Cartographic Modeling: The Analytical Capabilities of GIS. In: Goodchild, M., Parks, B. and Stewart, L. Eds., Environmental Modeling with GIS, Oxford University Press, Oxford.

[50] Saaty, T.L. (1980) The Analytic Hierarchy Process. McGraw Hill, New York.

[51] Deng, H. (1999) Multicriteria Analysis with Fuzzy Pair Wise Comparison. International Journal of Approximate Reasoning, 21, 215-231. https://doi.org/10.1016/S0888-613X(99)00025-0

[52] Hefny, H.A., Elsayed, H.M. and Aly, H.F. (2013) Fuzzy Multi-Criteria Decision-Making Model for Different Scenarios of Electrical Power Generation in Egypt. Egyptian Informatics Journal, 14, 125-133.

https://doi.org/10.1016/j.eij.2013.04.001 
[53] Saaty, R.W. (1987) The Analytic Hierarchy Process-What It Is and How It Is Used. Mathematical Modelling, 9, 161-176. https://doi.org/10.1016/0270-0255(87)90473-8

[54] Turksen, I.B. (2001) Operations Research and Management Science Applications of Fuzzy Theory. Analytical Review, 4, 45-48.

[55] Zadeh, L.A. (1965) Fuzzy Sets. Information and Control, 8, 338-353. https://doi.org/10.1016/S0019-9958(65)90241-X

[56] Wu, H.-Y., Tzeng, G.-H. and Chen, Y.-H. (2009) A Fuzzy MCDM Approach for Evaluating Banking Performance Based on Balanced Scorecard. Expert Systems with Applications, 36, 10135-10147.

[57] Elomda, B.M., Hefny, H.A. and Hassan, H.A. (2013) An Extension of Fuzzy Decision Maps for Multi-Criteria Decision-Making. Egyptian Informatics Journal, 14, 147-155. https://doi.org/10.1016/j.eij.2013.05.001

[58] Francesco Quatraro (2003) Cours de Macro-économie. http://hp.gredeg.cnrs.fr/Francesco_Quatraro/Cours\%20Micro/Micro\%2003.pdf

[59] El-Gendawy, A.H.S., Othman, A.A.E. and Mahmoud, A.H.A. (2013) Sustainable Decision-Making through Integrating Geographic Information Systems into the Entire Environmental Impact Assessment Process. SB13-Cairo, 1-16.

https://www.researchgate.net/publication/271906786_Sustainable_Decision-Making _through_Integrating_Geographic_Information_Systems_into_the_Entire_Environ mental_Impact_Assessment_Process

[60] Mahmoud, A., Shendi, M.M., Pradhan, B. and Attia, F. (2009) Utilization of Remote Sensing Data and GIS Tools for Land Use Sustainability Analysis: Case Study in El-Hammam Area, Egypt. Central European Journal of Geosciences, 1, 347-367. https://pdfs.semanticscholar.org/f521/70e12cb63839d4e86bbad47eb32e90be34c6.pdf

[61] Azizia, Z., Najafi, A. and Sohrabi, H. (2008) Forest Canopy Density Estimating, Using Satellite Images. The International Archives of the Photogrammetry, Remote Sensing and Spatial Information Sciences, 37, 1127-1130.

[62] https://www.indexdatabase.de/db/i.php?offset=1

[63] Sylvain, J.-D., Michaud, A.R., Nolin, M.C. and Bénié, G.B. (2012) A Novel Spectro-Temporal Approach for Predicting Soil Physical Properties. In: Minasny, B., Malone, B.P. and McBratney, A.B., Eds., Digital Soil Assessments and Beyond, Taylor and Francis Group, London, 381-386.

[64] Zha, Y., Gao, J. and Ni, S. (2003) Use of Normalized Difference Built-Up Index in Automatically Mapping Urban Areas from TM Imagery. International Journal of Remote Sensing, 24, 583-594. https://doi.org/10.1080/01431160304987

[65] Rasul, A., Balzter, H., Gaylan, R., Ibrahim, F., Hameed, H.M., Wheeler, J., Adamu, B., Ibrahim, S. and Najmaddin, P.M. (2018) Applying Built-Up and Bare-Soil Indices from Landsat 8 to Cities in Dry Climates. Land, 7, 81.

[66] Ngandam Mfondoum, A.H., Etouna, J., Simen, C., Tekuh, O. and Mvogo Moto, A.F. (2019) Participatory GIS and Decision-Making-Practical Cases in Agriculture, Health, Livestocks and Tourism in Cameroon. IAETSD Journal for Advanced Research in Applied Sciences, 6, 34-51.

http://www.iaetsdjaras.org/gallery/6-february-882.pdf

[67] Ngandam Mfondoum, A.H., Etouna, J., Nongsi, B.K., Mvogo Moto, F.A. and Noulaquape Deussieu, F.G. (2016) Assessment of Land Degradation Status and Its Impact in Arid and Semi-Arid Areas by Correlating Spectral and Principal Component Analysis Neo-Bands. International Journal of Advanced Remote Sensing and GIS, 5, 1539-1560. https://doi.org/10.23953/cloud.ijarsg.77 